\title{
CONTEXTOS VEGETALES DE ALEROS CON PINTURAS (PRECORDILLERA DE ARICA, NORTE DE CHILE)
}

\author{
Magdalena García ${ }^{1}$ y Marcela Sepúlveda
}

\section{* Introducción}

Resumen

Se presentan los resultados obtenidos del análisis de los restos vegetales provenientes de tres aleros con pinturas rupestres de la precordillera de Arica (extremo norte de Chile): sitios Pampa El Muerto 3 y 8 (PM-3 y PM-8) y Tangani 1 (TAN-1). A partir del material vegetal intentamos precisar las distintas actividades desarrolladas al interior de estos espacios y, de este modo, aproximarnos a los autores de estas manifestaciones rupestres en tiempos prehispánicos. Finalmente, discutimos nuestros resultados en relación con lo observado en otros contextos contemporáneos de la subárea Circumpuneña.

Palabras claves: restos vegetales - aleros - arte rupestre - pinturas rupestres - Arica - Atacama.

We present the results of the analysis of archaeological plant remains from rock shelters with paintings of Arica's precordillera (Northern Chile), specifically, we refer to Pampa El Muerto 3 and 8 (PM-3 and PM-8) and Tangani 1 (TAN-1) sites. With these results, we identified the different activities developed in these spaces and, thus, we try to document who could be the authors of these rock art manifestations in pre-Hispanic times. Finally, our results are discussed in relation to other contemporary sites of the Atacama region.

Key words: archaeological plant remains - rock shelters - painting Arica - Atacama.

Recibido: diciembre 2009. Aceptado: abril 2010.
Los estudios de los vegetales prehispánicos en la zona de Valles Occidentales del extremo norte de Chile se han desarrollado fundamentalmente en los valles bajos y en la costa, donde existe una preservación excepcional de los materiales orgánicos, producto de la extrema aridez que caracteriza esos ambientes. Estas condiciones posibilitan, además, que las diversas excavaciones realizadas a la fecha no requieran de la aplicación de tecnologías muy complejas para la recuperación y tratamiento de esta clase de restos, permitiendo así que en la actualidad dispongamos de un registro arqueobotánico variado y abundante que otorga cierta claridad en relación a la diversidad de especies recolectadas y los usos que se les otorgaron en el pasado.

Con ello, los contextos vegetales recuperados principalmente en los valles de Azapa y Lluta, y en la costa de Arica, representan universos materiales bastante heterogéneos referidos a ámbitos como la alimentación, la artesanía, la construcción, el forraje, el combustible, el vestuario, la textilería y la ornamentación, entre otros. Lo anterior se expresa en el registro arqueológico bajo diferentes evidencias que incluyen una gran variabilidad de ecofactos (frutos, semillas, hojas, tallos, maderas, espigas, raíces) y artefactos (madera tallada, virutas, cordelería, cestería, entre otros), con los cuales el especialista debe estar familiarizado botánica y etnográficamente, a fin de llevar a cabo su identificación taxonómica y su comprensión en términos de los usos que se les dieron a las diversas plantas en el pasado.

\footnotetext{
${ }^{1}$ Centro de Investigaciones del Hombre en el Desierto (CIHDE), www.cihde.com; Santa Victoria 45, Santiago Centro, Santiago, CHILE. Email: manegarciab@yahoo.com; manegarciab@gmail.com

2 Depto. de Antropología, Universidad de Tarapacá, 18 de Septiembre 2222. Casilla 6D, Arica, CHILE. Email: msepulveda@uta.cl; marcelaasre@gmail.com
} 


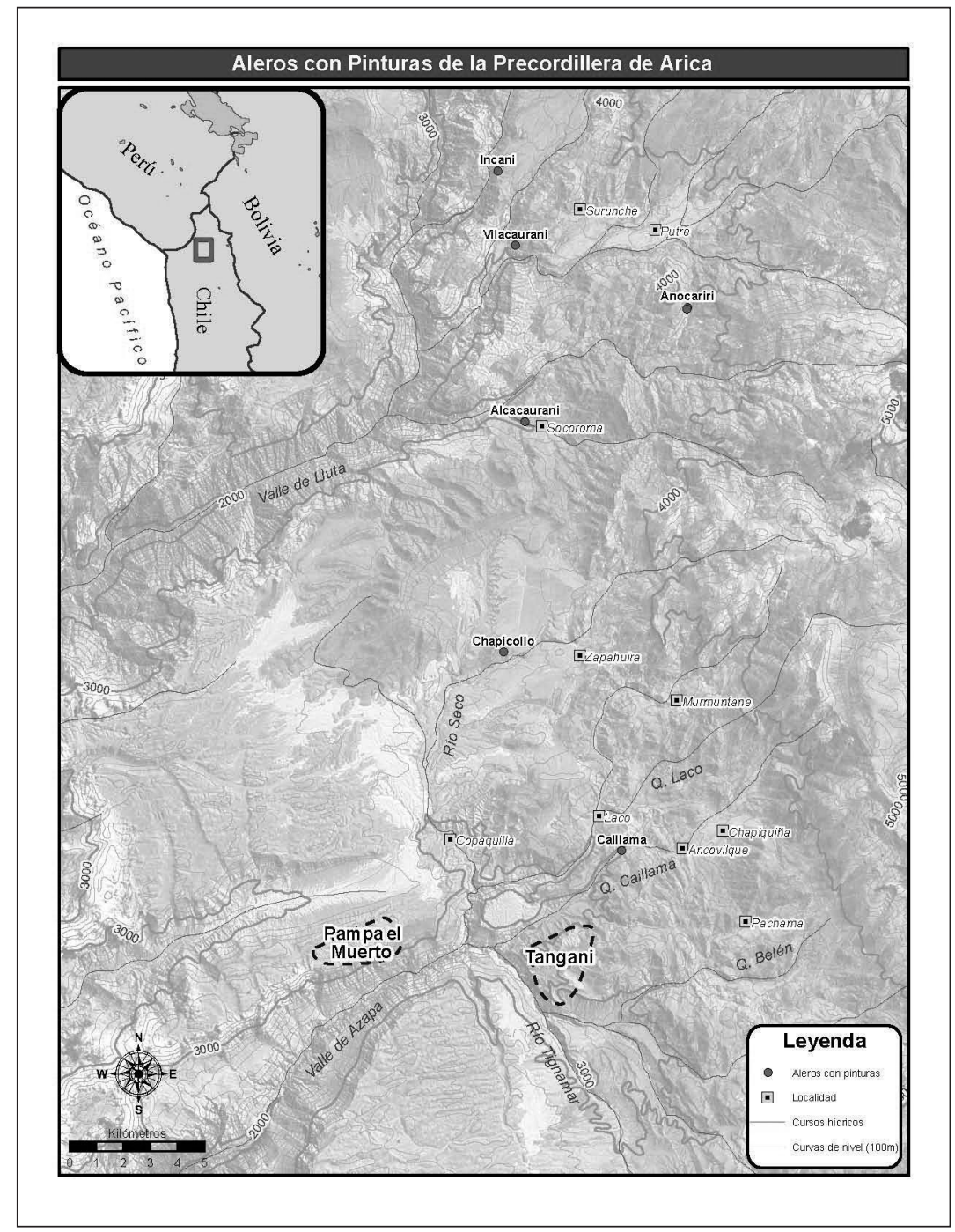

Figura 1. Mapa de la precordillera de Arica, extremo norte de Chile.

En contraste con la costa y valles bajos, hasta ahora existen escasas referencias arqueobotánicas de los contextos de tierras altas (precordillera y Puna Seca). Una de las principales razones que podría explicar esta situación es la presencia de fuertes lluvias estivales que impiden en gran medida su preservación al interior de los depósitos arqueológicos. Así, sólo bajo ciertas condiciones favorables, como el resguardo de un alero o muro, la carbonización y/o la dureza propia de algunas semillas (p.e., Opuntia sp.), es posible que se conserven algunos restos, generalmente de tamaño reducido, como frutos y semillas (carporrestos) cuya recuperación requiere la imple- mentación de metodologías específicas. De este modo, es probable que si hubo restos vegetales en los sitios precordilleranos excavados, éstos debieron perderse de forma irremediable en la malla de los harneros, considerando que en este medio ambiente la única estrategia que asegura su obtención efectiva es la extracción de muestras de sedimentos para flotación (Hastorf y Popper 1988; Pearsall 1988, 1989).

Teniendo presente lo anterior, debemos considerar que estaremos ante una fracción de lo que debió constituir el universo vegetal total en estos contextos, lo cual se en- 
cuentra indirectamente expresado no solo en el profundo conocimiento etnobotánico que manifiestan las sociedades andinas de la sierra (Villagrán et al. 1999; Villagrán y Castro 2004), así como en el protagonismo que adquieren los contextos vegetales contemporáneos de la costa y valles bajos. En efecto, éstos constituyen antecedentes fundamentales para argumentar que hacia el inicio del periodo Formativo, existiría ya un pleno manejo y conocimiento en torno a las propiedades específicas de las especies vegetales recolectadas.

En este trabajo analizamos esa fracción recuperada por flotación a partir de muestras tomadas durante la excavación de los aleros Pampa del Muerto 3 (PM-3), Pampa del Muerto 8 (PM-8) y Tangani i (TAN-1), situados en el piso precordillerano de la zona de Arica (Figura 1). Estos contextos, datados entre el Arcaico Tardío y el Formativo Temprano, se caracterizan por presentar escenas pintadas en sus paredes interiores (Niemeyer 1972; Santoro y Dauelsberg 1985; Sepúlveda 2008). Nuestro principal objetivo apunta a evaluar, a partir de los restos vegetales, las distintas actividades desarrolladas al interior de estos espacios para, de este modo, aproximarnos a los posibles autores de estas manifestaciones rupestres.

\section{* Los contextos vegetales de arica}

En los pisos bajos del extremo norte de Chile (costa y valles), los restos vegetales se registran desde las primeras ocupaciones humanas vinculadas al Complejo Chinchorro (8000 AP); específicamente, en relación con contextos que evidencian un conocimiento técnico de las propiedades de las plantas silvestres, las cuales debieron ser recolectadas en las aguadas y valles costeros. Entre sus usos, se destaca el manejo de ciertas maderas y tallos utilizados en los tratamientos de momificación, incluyendo especies que absorben líquidos (Equisetum giganteum) y otras que otorgan rigidez a los cuerpos. Del mismo modo, se constata un amplio manejo de fibras vegetales como cañas (Typha angustifolia), juncos (Scirpus sp.), totoras (Phragmites australis) y algodón (Gossypium spp.), todas las cuales se utilizaron para elaborar esteras, cordelería, lienzas, bolsas y cobertores púbicos (Núñez 1969; Schiappacasse y Niemeyer 1984; Standen 1991; Belmonte et al. 1995, 2001; Vidal 2010).
Hacia el Arcaico Tardío (4000-1400 AC), coincidente con la simplificación de las técnicas de momificación, los habitantes de la costa y los valles comienzan a manifestar cambios importantes en el manejo de los recursos vegetales. Por una parte, el uso de las materias primas vegetales se reorienta fundamentalmente hacia la elaboración de cestería, a su vez que aumenta notablemente el uso de fibras de origen animal para la cordelería. De forma simultánea, se incorporan tubérculos y cucurbitáceas cultivadas, como achira (Canna edulis), mandioca o yuca (Manihot esculenta), camote (Hipomea batata), zapallos (Cucurbita sp.) y calabazas (Lagenaria sp.), asociados tanto a los contextos domésticos como funerarios (La Capilla, Quiani 7, Camarones 15, Tiliviche 2). Por último, se registran también especies de la vertiente oriental, como el dardo elaborado en madera de chonta (Astrocarym chonta) hallado en Tiliviche 2 (Dauelsberg 1974; Focacci 1974; Rivera et al. 1974; Erices 1975; Santoro 1981, 1982; Muñoz 1982; Núñez y Standen 1984).

Posterior a esta fase que transita hacia un modo de vida basado en la producción de alimentos, los contextos vegetales de la costa y valles bajos continúan diversificándose con el surgimiento de formaciones aldeanas durante el Formativo Temprano (fase Azapa: 1400500 AC) y, fundamentalmente, en el Formativo Tardío (fase Alto Ramírez: 500 AC-300 DC). En estas fases, se plantea la existencia de una economía agromarítima pues se evidencia una mayor abundancia y diversidad de productos cultivados, como variedades de maíces (Zea mays), porotos (Phaseolus vulgaris), pallares (Phaseolus lunatus), ajíes (Capsicum sp.) y quínoa (probablemente muchas veces confundida con semillas de Opuntia sp.), formando parte, junto a las especies silvestres y cultivadas antes mencionadas, de las ofrendas funerarias de los llamados "enturbantados" de Playa Miller 7, Azapa 70, Azapa 122 y Azapa 12, en Arica y su valle, y de Conanoxa en la quebrada Camarones (Focacci 1974; Rivera 1975; Dauelsberg 1985; Santoro 2000). En estos contextos aumentan también los objetos y recursos de la vertiente oriental, como semillas de Mucuma elliptica junto a tubos y tabletas para consumir alucinógenos, lo que sugiere la presencia de plantas del oriente de los Andes. Otros ecofactos alóctonos están representados por plumas de aves tropicales y piel de felino hallados en Camarones 15 (Rivera et al. 1974); además, ciertos textiles locales y objetos 


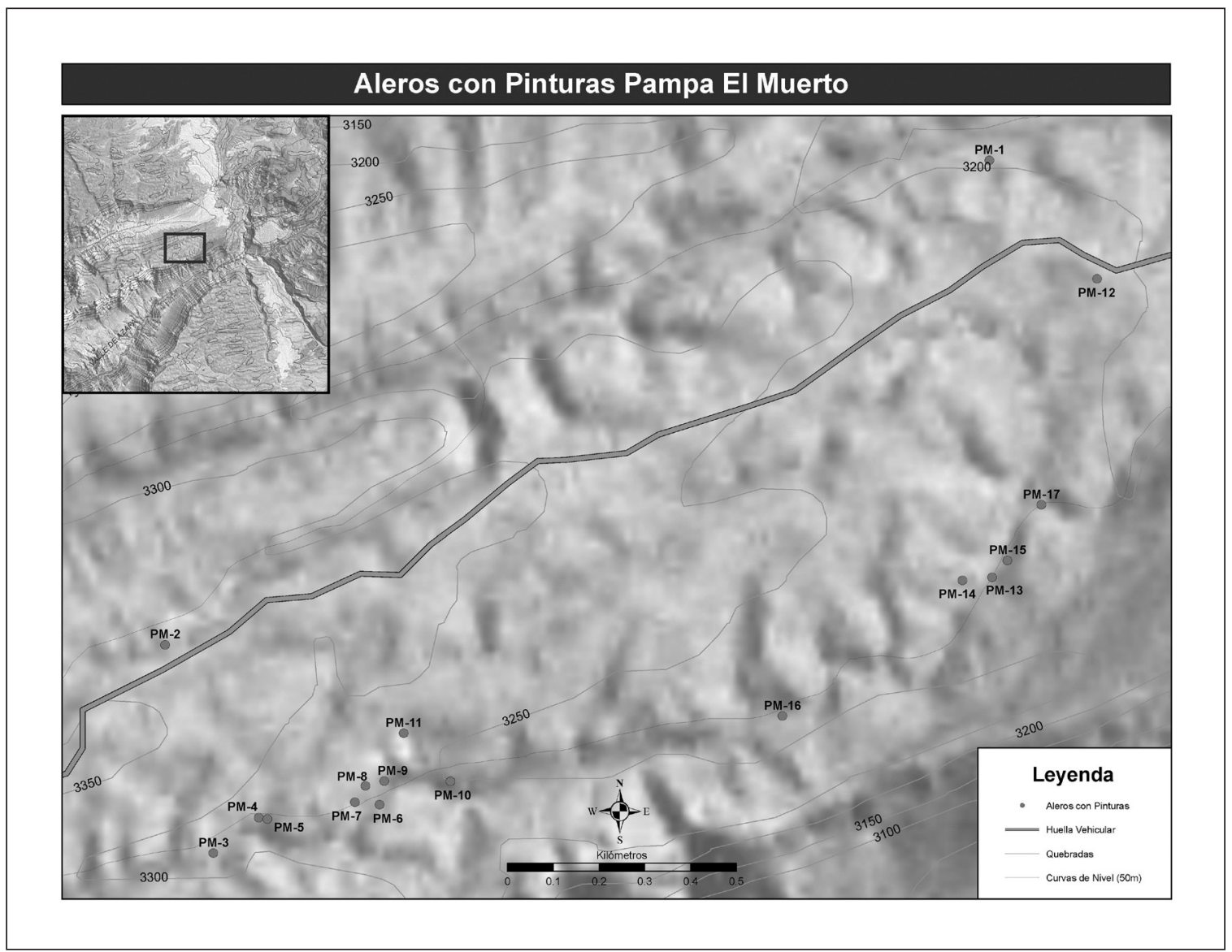

Figura 2. Ubicación de los aleros Pampa del Muerto 3 (PM-3) y Pampa del Muerto 8 (PM-8).

metalúrgicos plasman iconografía que algunos autores han relacionado con el Altiplano Central de Bolivia y Paracas, al sur de Perú (Focacci 1974; Rivera 1975; Muñoz 1989; Santoro 2000; Ayala 2001).

Frente a esta nueva situación característica del Formativo Tardío, los discursos arqueológicos expresan posturas diversas: aquellos que reconocen una sociedad post chinchorro, protagonista de sus propios procesos de transformación interna, y los que sugieren la presencia de colonias altiplánicas instaladas en los valles costeros ejerciendo una fuerte influencia sobre las comunidades locales (Dauelsberg 1974; Focacci 1974, 1980; Rivera et al. 1974; Rivera 1975, 1994; Muñoz 1982, 2001; Santoro 1982, 2000; Núñez 1989). No obstante, más allá de las diferencias, existe cierto consenso entre los investigadores en cuanto a que habría una intensificación de las relaciones a larga distancia durante la fase Alto Ramírez, lo cual no debe comprenderse como un fenómeno repentino, sino como un proceso con raíces de larga duración (Núñez y Dillehay 1995 [1978]; Focacci 1980; Muñoz 1982; Santoro 1982, 2000).

En este marco de desplazamiento o movilidad a larga distancia, los valles transversales del extremo norte de Chile, incorporados dentro de la subárea de Valles Occidentales, representaron corredores naturales para la articulación entre la costa y las tierras altas. A través de ellos, habrían circulado bienes y recursos naturales, además de ideas, conceptos y tecnologías propias de cada grupo, lo cual ha sido evidenciado en la mayoría de los aleros y abrigos rocosos de la precordillera donde se han recuperado materias primas líticas junto a restos arqueofaunísticos, además de elementos alóctonos como recursos marinos 
(diente de tiburón, conchas) y fragmentos cerámicos con desgrasante vegetal similar a los hallados en la costa, y que sostienen justamente la existencia de movilidad entre la costa y la cordillera (Niemeyer 1972; Santoro y Chacama 1982; Santoro y Dauelsberg 1985; Muñoz y Briones 1996; Schiappacasse y Niemeyer 1996; Sepúlveda 2008; Sepúlveda et al. $2009 \mathrm{Ms}$ ).

Los sitios estudiados, en esta instancia, entregaron varias dataciones sobre muestras de carbón provenientes de microeventos de fogones. Dos fechados obtenidos en PM-3 datan los comienzos de su ocupación durante el s. III AC, y una fecha obtenida de la primera capa la data cerca a 1450 DC. En PM-8 las dos dataciones realizadas indican una primera ocupación hacia $4500 \mathrm{AC}$, y una segunda durante los primeros siglos de nuestra era. De forma similar que en Pampa El Muerto, en TAN-1 habría un amplio rango cronológico de ocupación, con tres fechados vinculados al Arcaico Tardío (ca. 4000-2800 AC) y uno al período de los Desarrollos Regionales o Intermedio Tardío (ca. 1200 DC; Sepúlveda et al. 2009 $\mathrm{Ms})$. En conjunto, se observa entonces que los tres sitios presentan ocupaciones prolongadas, aunque correspondientes a eventos con baja densidad de material. Más específicamente, las ocupaciones se concentran durante el Arcaico Tardío y los últimos siglos anteriores a nuestra era, momento en que disminuyen hacia el período de Desarrollos Regionales, cuando estos espacios vuelven a reutilizarse al margen de grandes asentamientos o aldeas (Muñoz y Chacama 2006). De esta manera, de acuerdo a los datos obtenidos hasta el momento los episodios anteriores coinciden con la secuencia cronológica establecida para las tierras altas por Santoro y Chacama (1982) y Santoro (1989). No existe un correlato coherente para la última fase del Formativo o Alto Ramírez III (sensu Rivera 1994) y para el período Medio (Chacama 2004), a diferencia de lo observado en la costa y el valle, en los pisos bajos (Rivera 1994; Santoro 2000; Muñoz 2004; Chacama 2004).

Considerando lo anterior, este trabajo evalúa desde una nueva perspectiva los contextos arqueológicos precordilleranos vinculados a la transición Arcaico Tardío-Formativo, los cuales tradicionalmente han sido abordados desde el material lítico (Santoro 1989). De este modo, junto con aproximarnos a las actividades que se realizaron al interior de estos aleros, intentaremos comprender la forma como se articularon los distintos pisos altitudinales de la región.

\section{* Localización de los sitios y CARACTERIZACIÓN DEL ENTORNO NATURAL}

La precordillera o sierra de la región de Arica y Parinacota corresponde a la franja de tierra de 20 a $35 \mathrm{~km}$ de ancho comprendida entre 1900-2300 a 3200-3800 m.s.n.m. Constituye, de este modo, la antesala de la alta cordillera de los Andes, limitando por el oeste con los amplios valles costeros y por el oeste con el altiplano y la alta puna (6000 m.s.n.m.). Este espacio posee características geomorfológicas y climáticas propias, así como también una formación vegetacional que destaca por presentar la mayor abundancia y diversidad de especies en la región, debido a las lluvias estivales y temperaturas más cálidas en relación al altiplano (Villagrán y Castro 2004).

El relieve de la precordillera corresponde a una meseta alargada de origen volcánico y tectónico, con superficie regular y relativamente continua, que declina hacia el oeste en dos o tres grados (García et al. 2004: 11). En esta zona se originan los principales ríos de la región, Lluta, Azapa y Camarones, los cuales han sido utilizados como corredores naturales desde tiempos prehispánicos. Estas cuencas escurren de forma paralela en sentido este a oeste por cañones profundos que interrumpen la monotonía de la meseta desértica para finalmente desembocar en el océano Pacífico. Los sitios estudiados se encuentran en las cabeceras del valle de Azapa, específicamente en ambas laderas de la gran falla geológica precordillerana por donde fluyen los ríos Tignamar y Azapa: los sitios de Pampa El Muerto al este y Tangani al oeste.

Los aleros de Pampa del Muerto se ubican en el faldeo oriental de la sierra de Huaylillas, entre las quebradas de Azapa y Cardones (3100 m.s.n.m.), en el fondo de la quebrada homónima. Allí han sido reconocidos 17 aleros con pinturas (Figuras 2 y 3 ; Sepúlveda 2008), cuyas ocupaciones previamente han sido vinculadas a caravaneros y cazadores tardíos (Muñoz y Briones 1996). El sector se encuentra definido por un plano inclinado hacia el este, lo que permite que el agua estacional escurra por pequeñas quebradas hacia la localidad de Copaquilla. Los sitios excavados (PM-3 y PM-8), corresponden a cavidades formadas 


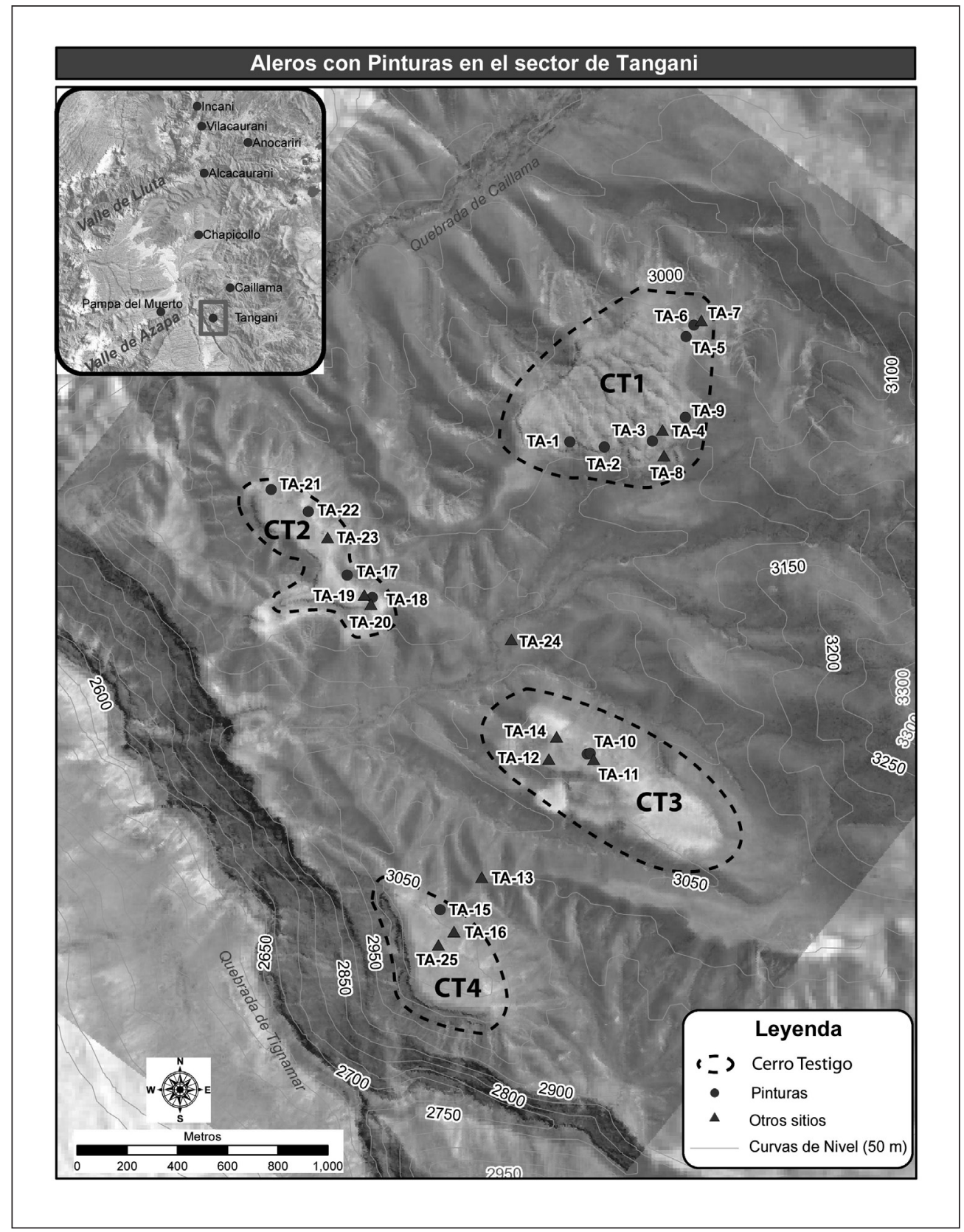

Figura 3. Ubicación del alero Tangani I (TAN-1).

por la erosión del viento sobre un sustrato rocoso conformado por ignimbritas que muestran fuertes indicios de deplacamiento ante los agentes naturales erosivos.

Por su parte, los sitios arqueológicos de Tangani se ubican en la meseta homónima, en la intersección de las que- bradas de Caillama y del río Tignamar (ver Figura 3), a una altura promedio de 3100 m.s.n.m. El alero Tangani 1 (TAN-1) forma parte de un conjunto de 13 sitios con pinturas rupestres, además de sitios con grabados, espacios pircados, corrales y un gran asentamiento prehispánico desconocido hasta ahora (Sepúlveda et al. 2010 Ms). La 
mayoría de los aleros corresponden a paredones rocosos de toba riolítica muy friable con escasas áreas de reparo o con una techumbre de roca. TAN-1 posee un techo rocoso que se desprende de la gran meseta. Varios de estos espacios están pircados, cerrados por muros, siendo utilizados como corrales hasta la década de 1960. Todo el sector es hasta la actualidad muy apreciado por guanacos que comúnmente pueden ser observados en las laderas de cerro o fondos de quebrada.

El clima fluctúa de árido a hiperárido, existiendo amplias oscilaciones térmicas entre el día y la noche. Las lluvias alcanzan un promedio de $60 \mathrm{~mm}$, con un máximo de 250 a $300 \mathrm{~mm}$ en los meses de diciembre a marzo (Santoro et al. 2003: 17), debido a la acción del fenómeno climático conocido como invierno altiplánico. De esta manera, la riqueza y distribución de la flora se relaciona con dos factores: precipitaciones y temperatura. Ambos se encuentran en una relación inversa, ya que a medida que aumentan las lluvias con la altitud, disminuyen las temperaturas. En este sentido, tanto la extensión de la cubierta vegetal (abundancia) como el número de especies (diversidad), encuentran sus valores mínimos en los extremos altitudinales inferior (piso desértico o prepuneño) y superior (pisos subnival y altoandino) debido a la extrema aridez y frigidez del clima, respectivamente. En los espacios intermedios (piso puneño o tolar), en tanto, se encuentran representadas la mayor cantidad y diversidad de especies de la región (Villagrán y Castro 2004). Complementariamente, existen ambientes azonales con sus características fitogeográficas propias, como los bofedales y las quebradas (Villagrán et al. 1999).

Los pisos vegetacionales aptos para la recolección vinculados a los aleros, corresponden al prepuneño (26003200 m.s.n.m.) y puneño (3300-4000 m.s.n.m.), junto con los ambientes azonales de quebrada. Con respecto al primero, son principalmente característicos ciertos arbustos como tíkara o chaspaksa (Ambrosia artemisioides), piyaya (Atriplex microphylla), tarasa (Tarasa operculata) y tomatillo (Lycopersicon chilensis); también, las especies columnares de cactáceas como sabaya (Browningia atacamensis) y cardón (Carryocactus brevistylus), y aquellas rastreras conocidas como jala jala (Opuntia sp.). Por último, se suma una densa cobertura de herbáceas o qhoras (Tagetes multiflora, Calandrinia thyrsoidea, Tetragonia microcarpa, Fagonia chilensis, Spergularia fasciculata, Cryptantha parviflora,
Cistanthe amaranthoides, Nolana tarapacana, Chaetanthera aymarae, Reyesia juniperoides) y gramíneas anuales o llapas (Munroa decumbens, Enneapogon desvauxii y Eragrostis nigricans), cuya germinación depende de las lluvias estivales (Villagrán et al. 1999).

La vegetación del piso puneño o tolar se caracteriza por presentar la más alta diversidad florística, destacando las formaciones de arbustos o tolas. Entre ellas, las más importantes son anqo pajariñi (Baccharis boliviensis), ñaka (Baccharis santelices y Baccharis tola), kipa (Fabiana ramulosa), purisa (Balbisia microphylla), añawaya (Adesmia spinosissima) y flor de manzanilla (Diplostephium meyenii), entre otras (Villagrán et al. 1999).

Finalmente, la vegetación de las quebradas posee una composición botánica singular, destacando ciertas especies arbóreas que crecen exclusivamente en estos ambientes, como waqan (Myrica pavonis), qero (Escallonia angustifolia), molle (Schinus molle), chañar (Geoffroea decorticans) y algarrobo (Prosopis alba), todos los cuales son enormemente significativos en la tradición andina (Villagrán et al. 1999). Entre los arbustos o tolas, también con multiplicidad de usos, encontramos las especies de pichana (Baccharis sp.) a cuyas raíces se asocia estacionalmente una planta parasitaria conocida como amañoko (Ombrophytum subterraneum) que otorga piñas comestibles altamente apetecidas. También son recurrentes la visa visa (Trixis cacalioides), la sapama (Ophryosporus pinifolius), la tajtaja (Lophopappus tarapacanus) y la sorona (Tessaria absinthioides). Adyacente a la ribera de los ríos hay cortadera (Cortaderia atacamensis), cañaveral (Phragmites australis) y qosqosa (Equisetum giganteum). Por último, son de gran importancia las malezas que crecen asociadas a las chacras, las cuales poseen variados usos, como las distintas variedades de yuyos (Chenopodium sp.) (Villagrán et al. 1999).

Considerar estos antecedentes permite, en primer lugar, conocer la diversidad de plantas con las cuales pudieron interrelacionarse las sociedades en el pasado y, en segundo lugar, comprender los procesos de formación de estos sitios. En este sentido, es significativa la presencia de ciertas semillas de hierbas locales en los depósitos excavados, cuyo ingreso se explica por factores naturales como el viento, generando una sobrerrepresentación de estos taxones en el registro arqueológico. 


\section{* ExcAVACión y ANÁlisis De los Restos VEGETALES}

Tanto en Pampa del Muerto como en Tangani se trazaron cuadrículas de 1 x $1 \mathrm{~m}$ al interior de los aleros. La excavación se realizó siguiendo la estratigrafía natural de los depósitos, subdividiendo en niveles artificiales las capas mayores a $5 \mathrm{~cm}$ de espesor. En términos generales, se detectaron depósitos poco densos, compuestos por pequeños fogones o microeventos, lo cual sugiere actividades y ocupaciones intermitentes de corta duración. Junto a los vegetales, los restos asociados corresponden principalmente a material lítico (desechos bifaciales e instrumentos expeditivos) $y$, en menor medida, a huesos de animales, material malacológico, plumas pequeñas y mineral de cobre, que hacen pensar en individuos que se trasladaban entre diferentes zonas ecológicas (Sepúlveda et al. $2009 \mathrm{Ms}$ ). Asimismo, se tomaron muestras de suelo (1 lt por nivel) para análisis químicos que contribuyeran a precisar los procesos de formación de los sitios (Ogalde y Sepúlveda 2009 Ms; Sánchez y Melgarejo 2009). Finalmente, se tomaron muestras de sedimento para flotación (1 lt por nivel) con el objeto de llevar a cabo un análisis exhaustivo sobre la presencia y comportamiento espacial y estratigráfico de los restos vegetales preservados. Cada una de estas muestras fue embolsada y etiquetada, consignando los criterios básicos de excavación (sitio, unidad, capa y nivel).

El muestreo para flotación estuvo dirigido hacia algunas de las unidades excavadas en los distintos aleros. En el caso de $\mathrm{PM}-3$ se excavaron seis unidades, de las cuales $\mathrm{C}_{1}, \mathrm{C}_{5}$ y D2 fueron seleccionadas por hallarse debajo de los paneles pintados o en sectores de mayor depresión superficial. De este sitio fue flotado un total de $37,56 \mathrm{lt}$ de sedimentos, con una muestra promedio de 1,04 lt por nivel (Figura 4). En PM-8 se excavó únicamente la unidad B4, con un total de 9,06 lt flotados y una muestra promedio de 0,9 lt por nivel estratigráfico (Figura 5). Por último, en TAN-1 se excavaron las unidades $\mathrm{C}_{4}$ y $\mathrm{D}_{4}$, donde los sedimentos flotados sumaron 50,32 lt, con una muestra promedio de 2,66 lt por nivel (Figura 6).

Tanto la flotación como el análisis de laboratorio fueron realizados en el Museo Universidad de Tarapacá, San Miguel de Azapa. El primero corresponde al proceso de separación de los elementos vegetales entre los sedimen-

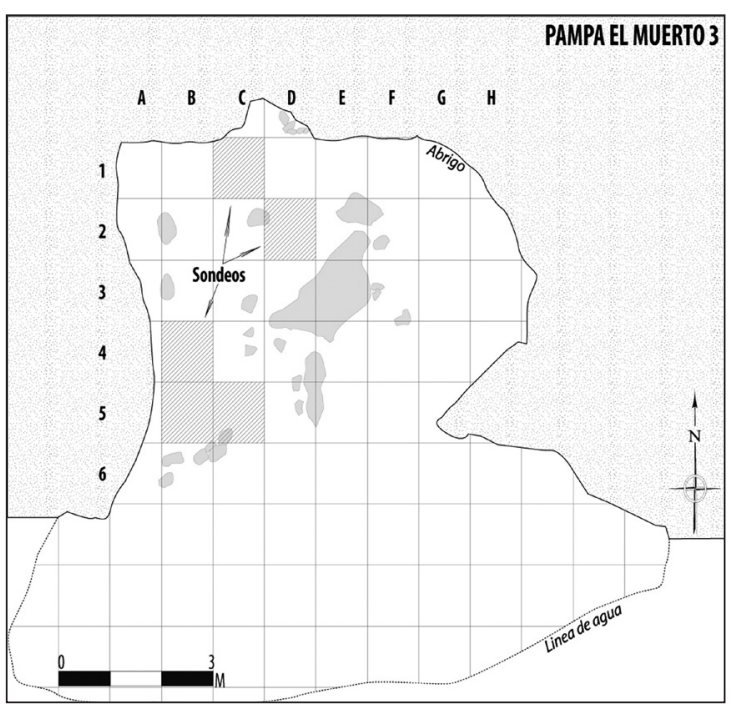

Figura 4. Unidades excavadas en PM-3.

tos, lo cual se lleva a cabo humedeciendo cada muestra en una máquina de flotación. Una vez que el material se encontró seco, las fracciones livianas (material flotante) fueron observadas íntegramente bajo una lupa binocular utilizando aumentos de o, 8 a $5 \mathrm{X}$. En este proceso se fueron extrayendo y cuantificando frutos y semillas, para finalmente depositarlos en tubos eppendorff rotulados con los datos respectivos de proveniencia. El criterio de cuantificación consideró una unidad cuando estuvo presente más de la mitad del carporresto $(+50 \%)$.

Finalmente, la determinación taxonómica de los restos se llevó a cabo a partir de la observación de formas, colores, tamaños y texturas de los restos, siguiendo el supuesto de que al deshidratarse, los restos quedan con cicatrices imperecederas que pueden ser comparadas con material de referencia (E. Belmonte, com. pers. 2010). Los ejemplares utilizados como referencia son tanto actuales como arqueológicos; los primeros son parte de la colección de las autoras y del herbario personal de Claudio Latorre, mientras que los segundos provienen de contextos excavados de la precordillera de Tarapacá; éstos complementan a los anteriores en la medida que permiten conocer las diversas formas de preservación que adopta el material al deshidratarse o carbonizarse (García 2007).

3 Ciencias Biológicas, Pontificia Universidad Católica de Chile. 


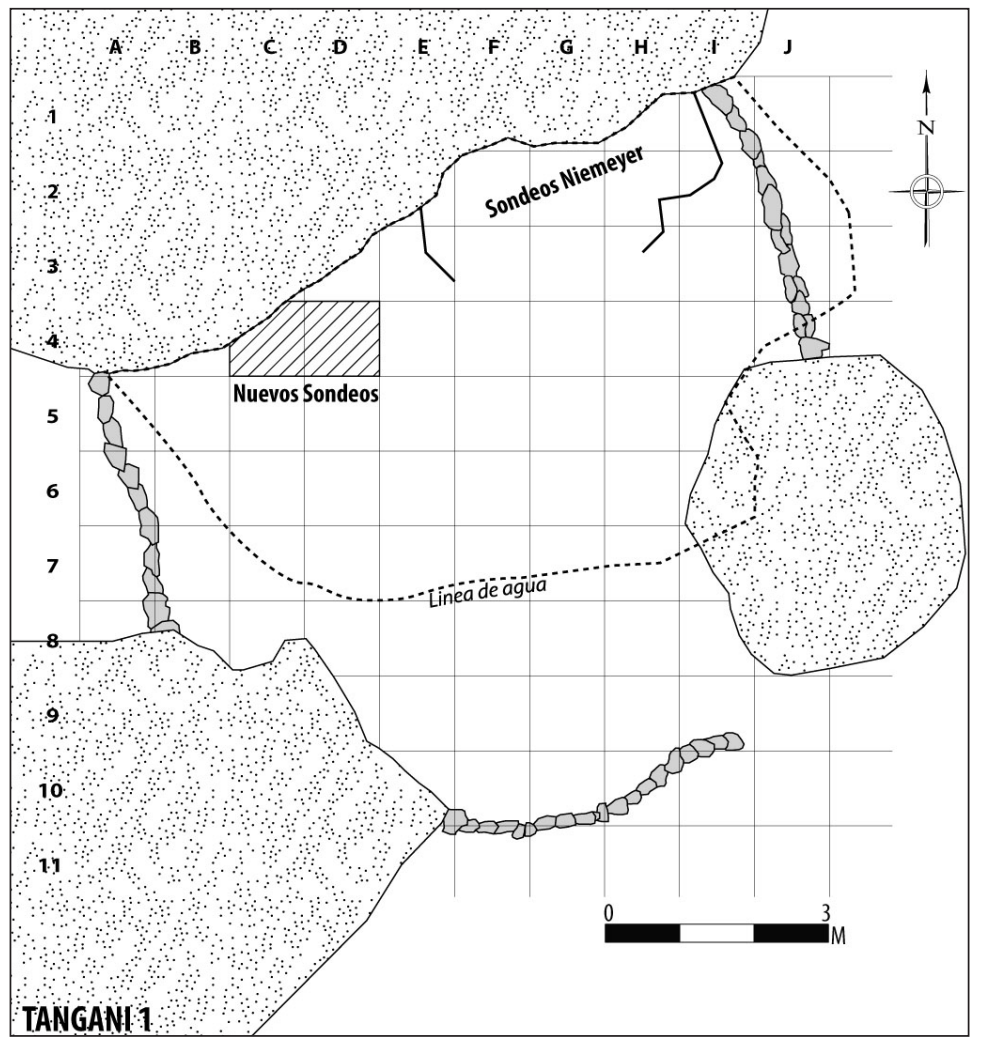

Figura 5. Unidades excavadas en PM-8

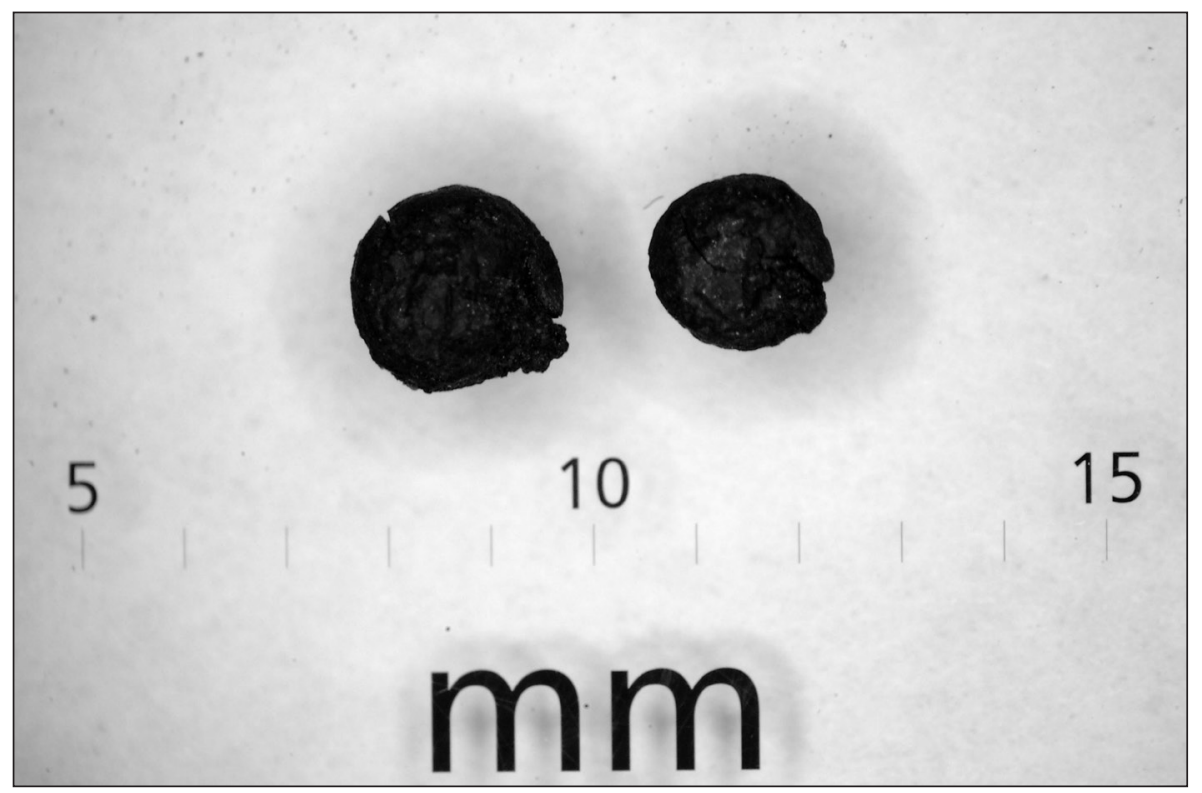

Figura 6. Semillas de frutos de opuntia (Opuntia sp.) consumidos como alimento. TAN-1, unidad D4, capa 2, nivel 5 SO. 


\section{* Contextos vegetales de pampa el muerto}

\section{Pampa El Muerto 3 (PM-3)}

En este sitio, se identificó un total de nueve taxones, de los cuales siete se consideraron de ingreso natural (post depositacional) debido a su recurrencia en el entorno del alero y a la fácil dispersión de sus semillas. Estos son Ambrosia artemisioides Meyen \& Walp. (tíkara macho), Cistanthe sp., Cristaria dissecta Hook. et Arn. E. (malvisco), Ephedra sp., Exodeconus integrifolius Phil. (oreja de ratón), Galium sp., Sisymbrium sp. y Tarasa operculata Cav. (malva).

Sobre las dos especies de origen cultural, destacan en gran medida las semillas de aquellas cactáceas conocidas genéricamente como jala jala (Opuntia sp.), las cuales suman 105 unidades con una densidad promedio de 2,8 (sem/lt). Con relación al estado de conservación, la mayor parte se preserva de forma carbonizada (91,42\%), mientras que el resto se encuentra deshidratado y protegido por la dureza exterior de las semillas (Pearsall 1988). Espacialmente, Opuntia se distribuye en las tres unidades muestreadas, aunque de forma bastante heterogénea a lo largo de las ocupaciones. La mayor concentración se encontró en la unidad $\mathrm{C}_{5}$ donde se contabilizaron 85 semillas, sobresaliendo ampliamente en relación a D2 y $\mathrm{C} 1$, donde sumaron 16 y 4, respectivamente. En estratigrafía, todos los restos tienden a concentrarse en la capa 2 , destacando nuevamente $\mathrm{C}_{5}$ que arroja una densidad máxima de 15,06 sem/lt, seguido por D2 con $4 \mathrm{sem} / \mathrm{lt}$ y, por último, $\mathrm{Cl}_{1}$ con $2 \mathrm{sem} / \mathrm{lt}$. En contraste, las capas superficiales (sup. y 1) e inferiores ( 3 y 4 ) presentan indíces nulos o cercanos (Tabla 1).

Varias especies de Opuntia sp. (conocidas como pega pega, kume y tuna) son frecuentes en los pisos prepuneños y puneños de los Andes del norte de Chile (2700-3000 m.s.n.m.), las cuales se caracterizan por ser rastreras y formar grandes cojines de 10 a $20 \mathrm{~cm}$ de diámetro y $10 \mathrm{~cm}$ de alto (Hoffmann 1989; Villagrán y Castro 2004). Sus semillas son esféricas, teniendo 3,5 a $4 \mathrm{~mm}$ de diámetro, y una cubierta dura que favorece su preservación y arilo resaltado (Pearsall 1988; Hoffmann 1989). Etnográficamente, se ha documentado el uso comestible y medicinal de sus frutos, los cuales antiguamente eran consumidos, principalmente por los niños, con azúcar. Es de sabor ácido como el limón, perfectamente comestible al natural y muy agradable para combatir la sed. Junto con los frutos, las paletas (karas o pencas) se consumen en sopas mientras que la pulpa se utiliza para preparar mermeladas, melcochas, jaleas y bebidas. Asimismo, se considera un excelente cicatrizante, remedio para enfermedades del hígado y la diabetes, para la vejiga, el resfrío, la garganta, alivia la tos seca, la tos convulsiva, la fiebre, y en ayunas es muy poderoso para disolver cálculos por la acidez de los frutos; además, en cosmetología se usa para quitar las manchas cutáneas. Finalmente, también es utilizado como forraje, sobre todo para llamas, cabras y burros, y las raíces de algunas especies también son comestibles (Villagrán et al. 1998, 1999; Villagrán y Castro 2004; Pardo y Pizarro 2005; Novoa 2006).

Un segundo taxón de origen cultural en PM-3 es el maíz (Zea mays L.), el cual está representado por una mazorca o marlo procedente de la capa 1 , y un grano carbonizado en los inicios de la capa 2. Considerando que su comportamiento estratigráfico se opone al de las semillas de Opuntia sp., se puede inferir que el transporte y consumo de maíz en el alero es posterior a las ocupaciones que registran la importancia de la recolección de cactáceas.

\section{Pampa El Muerto 8 (PM-8)}

Al igual que en PM-3, en este sitio los contextos vegetales están representados principalmente por semillas de cactáceas recuperadas por flotación. No obstante, PM-8 documenta procesos de formación diferentes al anterior, a juzgar por la ausencia de semillas propias del entorno que pudieran haber ingresado por acción del viento o arrastre.

Se analizaron 111 carporrestos asociados a la única unidad excavada (B4), correspondientes a tres especies vegetales, entre las cuales se replica el protagonismo de Opuntia sp. con 107 semillas. Los carporrestos restantes se vinculan a aff. Oreocereus spp., un género de cactácea local que también ofrece frutos carnosos, y a Prosopis sp. (algarrobo), ambos representados por dos semillas cada uno.

Los restos tienden a concentrarse en los niveles superiores, principalmente en la capa 1 con una densidad de 56,2 $\mathrm{sem} / \mathrm{lt}$, luego en la capa 2 con un promedio de $20 \mathrm{sem} /$ lt. Las capas 3 y 4 no presentan ningún tipo de evidencia vegetal. Es significativo destacar que la presencia de las semillas de cactáceas y algarrobo implican el consumo in situ de sus frutos, ya que es en ese momento en el cual se 


\begin{tabular}{|c|c|c|c|c|c|c|}
\hline Unidad & Capa & Nivel & Volumen (lt) & $\mathbf{N}$ & Carbonización & Densidad (sem/lt $)$ \\
\hline $\mathrm{C}_{1}$ & sup. & & 1,15 & 1 & o & 0,87 \\
\hline $\mathrm{C} 1$ & 2 & & 1,5 & 3 & 1 & 2,00 \\
\hline$C_{5}$ & 2 & 1 & 1,3 & 1 & 1 & 0,77 \\
\hline $\mathrm{C}_{5}$ & 2 & rasgo 1 & 1,5 & o & o & 0,00 \\
\hline $\mathrm{C}_{5}$ & 2 & 2 & 1,5 & 14 & 14 & 9,33 \\
\hline $\mathrm{C}_{5}$ & 2 & 3 & 3,52 & 53 & 53 & 15,06 \\
\hline $\mathrm{C}_{5}$ & 3 & rasgo 3 & 1,45 & 4 & 4 & 2,76 \\
\hline $\mathrm{C}_{5}$ & 3 & rasgo 4 & 1,91 & 1 & 1 & 0,52 \\
\hline $\mathrm{C}_{5}$ & 3 & rasgo 5 & 0,95 & 6 & o & 6,32 \\
\hline $\mathrm{C}_{5}$ & 3 & rasgo 6 & 1,38 & 3 & 3 & 2,17 \\
\hline $\mathrm{C}_{5}$ & 3 & entre rasgos & 1,5 & 2 & 2 & 1,33 \\
\hline $\mathrm{C}_{5}$ & 3 & 2 & 1 & 1 & 1 & 1,00 \\
\hline $\mathrm{C}_{5}$ & 4 & 1 & 1,35 & o & o & 0,00 \\
\hline $\mathrm{C}_{5}$ & 4 & rasgo 7 & 1,4 & o & o & 0,00 \\
\hline $\mathrm{D}_{2}$ & 1 & 1 & 1,5 & o & o & 0,00 \\
\hline D2 & 1 & rasgo 1 & 1 & o & o & 0,00 \\
\hline D2 & 2 & 1 & 1,5 & 2 & 2 & 1,33 \\
\hline $\mathrm{D}_{2}$ & 2 & rasgo 1 & 1,25 & 5 & 5 & 4,00 \\
\hline D2 & 2 & 2 & 1,5 & 3 & 3 & 2,00 \\
\hline D2 & 2 & rasgo 2 & 1,5 & o & o & 0,00 \\
\hline$D_{2}$ & 2 & 3 & 1,5 & 6 & 6 & 4,00 \\
\hline $\mathrm{D}_{2}$ & 3 & 1 & 1,4 & $\circ$ & $\circ$ & 0,00 \\
\hline $\mathrm{D}_{2}$ & 3 & rasgo 3 & 0,5 & o & o & 0,00 \\
\hline $\mathrm{D}_{2}$ & 3 & 2 & 1,5 & o & o & 0,00 \\
\hline $\mathrm{D}_{2}$ & 3 & 3 & 1,5 & $\circ$ & o & 0,00 \\
\hline D2 & 4 & 1 & 1,5 & $\circ$ & ○ & 0,00 \\
\hline \multicolumn{3}{|c|}{ Total } & 37,56 & 105 & 96 & 2,80 \\
\hline
\end{tabular}

Tabla 1. Distribución y densidad de las semillas de Opuntia sp. en las unidades excavadas de PM-3. Se destacan las máximas densidades de cada taxón en ambas unidades excavadas.

descartan (y/o escupen) las semillas que pasan a formar el registro arqueológico.

En relación al comportamiento estratigráfico de Opuntia sp., la mayor concentración ocurre en la capa 1 con una densidad de $55 \mathrm{sem} / \mathrm{lt}$, seguida por la capa 2 con 18,8 sem/lt. Por su parte, los restos identificados como aff. Oreocereus spp. se distribuyen en los niveles 1 y 4 de la capa 2, con una densidad de 1,1 sem/lt y o,6 sem/lt, respectivamente. Por último, las semillas de algarrobo (Prosopis sp.) se asocian a la capa 1 y presentan una densidad de 1,25 sem/lt (Tabla 2).
$\mathrm{Al}$ igual que Opuntia sp., el género Oreocereus también es relativamente frecuente en la precordillera de Arica estando representado por las especies $O$. leucotrichus, $O$. variicolor y $O$. hempelianus, de las cuales las dos primeras poseen frutos redondos y carnosos (Hoffmann 1989) que podrían resultar comestibles. Por su parte, la etnografía se refiere únicamente a Oreocereus leucotrichus (Phil.), conocido como cactus blanco y tunilla, entre otros, señalándola como una especie columnar abundante en los tolares de la precordillera de Arica e Iquique, característica por la lana blanca que la cubre y la importancia alimentaria de sus frutos amarillos de $5 \mathrm{~cm}$ diámetro, los cuales son 


\begin{tabular}{|c|c|c|c|c|c|c|c|}
\hline Unidad & Capa & Nivel & Taxón & $\mathbf{N}$ & Carbonización & Volumen (lt $)$ & Densidad (sem/lt) \\
\hline $\mathrm{B}_{4}$ & 1 & 1 & Opuntia sp. & 88 & 1 & 1,6 & 55,00 \\
\hline $\mathrm{B}_{4}$ & 1 & 1 & Prosopis sp. & 2 & o & 1,6 & 1,25 \\
\hline $\mathrm{B}_{4}$ & 2 & 1 & Opuntia sp. & 16 & o & 0,85 & 18,82 \\
\hline $\mathrm{B}_{4}$ & 2 & 1 & aff. Oreocereus spp. & 1 & o & 0,85 & 1,18 \\
\hline $\mathrm{B}_{4}$ & 2 & 2 & Opuntia sp. & 1 & o & 1,4 & 0,71 \\
\hline $\mathrm{B}_{4}$ & 2 & 3 & Opuntia sp. & 1 & 1 & 1,45 & 0,69 \\
\hline $\mathrm{B}_{4}$ & 2 & 4 & Opuntia sp. & 1 & ० & 1,45 & 0,69 \\
\hline $\mathrm{B}_{4}$ & 2 & 4 & aff. Oreocereus spp. & 1 & o & 1,45 & 0,69 \\
\hline $\mathrm{B}_{4}$ & 3 & 1 & sin material & ० & ○ & 0,86 & 0,00 \\
\hline $\mathrm{B}_{4}$ & 4 & 1 & sin material & $\circ$ & o & 1,45 & 0,00 \\
\hline \multicolumn{4}{|c|}{ Total } & 111 & 2 & 9,06 & 12,25 \\
\hline
\end{tabular}

Tabla 2. Diversidad, distribución y densidad de los carporrestos en la unidad B4 de PM-8. Se destacan las máximas densidades de cada taxón en ambas unidades excavadas.

\begin{tabular}{|c|c|c|c|}
\hline Taxón & Evidencia & $\mathbf{N}$ & Carbonización \\
\hline Chenopodium sp. (yuyo) & Semilla & 3 & 3 \\
\hline Opuntia sp. (jala jala, tuna) & Semilla & 415 & 74 \\
\hline Stipa sp. (paja blanca) & tallo y bulbo & presente & ausente \\
\hline aff. Oreocereus spp. & Semilla & 43 & 2 \\
\hline Brassicaceae & Hoja & presente & ausente \\
\hline Chenopodiaceae & Semilla & 196 & 139 \\
\hline \multicolumn{2}{|l|}{ Total } & 561 & 218 \\
\hline
\end{tabular}

Tabla 3. Diversidad de especies identificadas en TAN-1. Se cuantifican los carporrestos.

algo ácidos y se comen con sal (Hoffmann 1989; Villagrán y Castro 2004).

\section{Contextos vegetales en Tangani (TAN-1)}

El material vegetal de TAN-1 corresponde principalmente a semillas recuperadas por flotación, a excepción de un conglomerado de pajas y hojitas que fue extraído de forma directa ( $\mathrm{C}_{5}$ rasgo 4 ). En términos generales, los contextos vegetales de este sitio dan cuenta de una mayor diversidad de especies y tipos de evidencias (semillas, hojas y tallos) en relación con los aleros de Pampa del Muerto, aunque nuevamente destacan las semillas de cactáceas (Tabla 3).
En términos generales, se reconoció un total de 14 taxones, de los cuales ocho corresponden a especies locales cuyas semillas poseen una fácil y amplia dispersión producto del viento. Estas últimas las hemos considerado de ingreso natural al depósito y corresponden a Adesmia sp., Ambrosia artemisioides Meyen \& Walp. (tíkara macho), Cistanthe sp., Criptantha sp., Cristaria dissecta Hook. et Arn. (malvisco), Ephedra sp., Krameria lappacea (Dombey) Burdet \& Simpson (tíkara hembra) y una especie de la familia Verbenaceae.

Respecto a las evidencias culturales, se analizó un total de 561 semillas junto a restos no cuantificables como el conglomerado vegetal antes mencionado. Por una parte, se registraron 415 semillas de Opuntia sp. $(17,83 \%$ carbonizadas) y, por otra, 43 semillas similares a las observadas en PM-8 determinadas como aff. Oreocereus spp. (4,65\% carbonizadas). Las primeras se distribuyen homogéneamente tanto en $\mathrm{C}_{4}$ como en $\mathrm{D}_{4}$, con una mayor densidad asociada a los niveles medios, donde se registró una densidad máxima de 37,69 sem/ lt y $20 \mathrm{sem} / \mathrm{lt}$, respectivamente (Tabla 4). Sobre las segundas, la mayor densidad se encuentra en los niveles superiores, principalmente en la unidad $\mathrm{C}_{4}$ con 8,46 sem/lt (Figura 7).

Por otra parte, se reconocieron 199 semillas carbonizadas de la familia Chenopodiaceae, las cuales se distribuyen en 


\begin{tabular}{|c|c|c|c|c|c|c|}
\hline Unidad & Capa & Nivel & $\mathbf{N}$ & Carbonización & Volumen $(1 \mathbf{t})$ & Densidad (sem/lt $)$ \\
\hline $\mathrm{C}_{4}$ & 2 & 1 & 51 & 1 & 2,6 & 19,62 \\
\hline $\mathrm{C}_{4}$ & 2 & 2 rasgo 2 & 24 & 7 & 3 & 8,00 \\
\hline $\mathrm{C}_{4}$ & 2 & 2 rasgo 3 & 63 & 2 & 2,66 & 23,68 \\
\hline $\mathrm{C}_{4}$ & 2 & 2 base fogón & 52 & 16 & 2,6 & 20,00 \\
\hline $\mathrm{C}_{4}$ & 2 & 3 & 13 & 2 & 2,6 & 5,00 \\
\hline $\mathrm{C}_{4}$ & 2 & $3(\mathrm{~S})$ rasgo 3 & 14 & o & 2,2 & 6,36 \\
\hline $\mathrm{C}_{4}$ & 2 & 3 rasgo 4 & 98 & 2 & 2,6 & 37,69 \\
\hline $\mathrm{D}_{4}$ & 1 & 2 & 6 & 5 & 2,7 & 2,22 \\
\hline $\mathrm{D}_{4}$ & 1 & 2 rasgo 1 & 5 & 5 & 3,15 & 1,59 \\
\hline $\mathrm{D}_{4}$ & 1 & 2 rasgo 2 & 3 & 3 & 3 & 1,00 \\
\hline $\mathrm{D}_{4}$ & 2 & $1(\mathrm{NO})$ & 4 & 4 & 2,55 & 1,57 \\
\hline $\mathrm{D}_{4}$ & 2 & I(E) & 6 & 6 & 2,9 & 2,07 \\
\hline $\mathrm{D}_{4}$ & 2 & $2(E)$ & 28 & 14 & 3,3 & 8,48 \\
\hline $\mathrm{D}_{4}$ & 2 & 2 rasgo 5 & o & ० & 2,21 & 0,00 \\
\hline $\mathrm{D}_{4}$ & 2 & $3(\mathrm{SO})$ & 40 & 5 & 2 & 20,00 \\
\hline $\mathrm{D}_{4}$ & 2 & 4 & $\circ$ & o & 2,75 & 0,00 \\
\hline $\mathrm{D}_{4}$ & 2 & 5 & 8 & 2 & 1,8 & 4,44 \\
\hline $\mathrm{D}_{4}$ & 2 & 5 rasgo 7 & $\circ$ & o & 2,9 & 0,00 \\
\hline $\mathrm{D}_{4}$ & 2 & 5 rasgo 9 & 3 & 1 & 2,8 & 1,07 \\
\hline \multicolumn{3}{|c|}{ Total } & 415 & 74 & 50,32 & 8,25 \\
\hline
\end{tabular}

Tabla 4. Distribución y densidad de las semillas de Opuntia sp. en TAN-1. Se destacan las máximas densidades de cada taxón en ambas unidades excavadas.

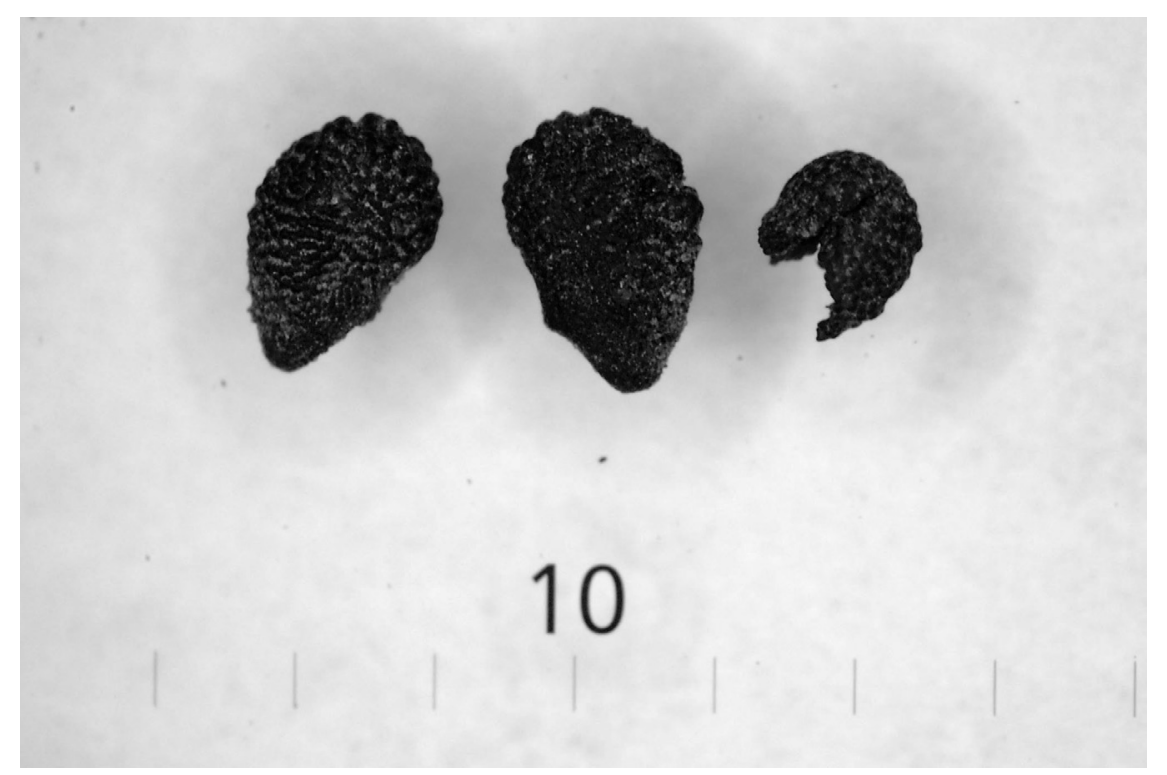

Figura 7. Semillas de frutos de cactáceas (aff. Oreocereus spp.) consumidos como alimento. TAN-1, unidad C4, rasgo 2. 


\begin{tabular}{|c|c|c|c|c|c|c|}
\hline Unidad & Capa & Nivel & Taxón & $\mathbf{N}$ & Carbonización & Densidad (sem/lt.) \\
\hline $\mathrm{C}_{4}$ & 2 & 1 & aff. Oreocereus spp. & 22 & o & 8,46 \\
\hline $\mathrm{C}_{4}$ & 2 & 2 rasgo 2 & Chenopodium sp. & 1 & 1 & 0,33 \\
\hline $\mathrm{C}_{4}$ & 2 & 2 rasgo 2 & aff. Oreocereus spp. & 3 & o & 1 \\
\hline $\mathrm{C}_{4}$ & 2 & 2 rasgo 3 & aff. Oreocereus spp. & 1 & o & 0,37 \\
\hline $\mathrm{C}_{4}$ & 2 & 2 base fogón & aff. Oreocereus spp. & 2 & o & 0,76 \\
\hline $\mathrm{C}_{4}$ & 2 & 3 & Chenopodiaceae & 1 & o & 0,38 \\
\hline $\mathrm{C}_{4}$ & 2 & $3(\mathrm{~S})$ rasgo 3 & aff. Oreocereus spp. & 1 & o & 0,45 \\
\hline $\mathrm{C}_{4}$ & 2 & 3 rasgo 4 & F. Chenopodiaceae & 2 & o & 0,76 \\
\hline $\mathrm{D}_{4}$ & 1 & 2 & aff. Oreocereus spp. & 2 & ० & 0,74 \\
\hline $\mathrm{D}_{4}$ & 1 & 2 & Chenopodiaceae & 54 & o & 20 \\
\hline $\mathrm{D}_{4}$ & 1 & 2 rasgo 1 & aff. Oreocereus spp. & 3 & o & 0,95 \\
\hline $\mathrm{D}_{4}$ & 1 & 2 rasgo 1 & Chenopodiaceae & 2 & 2 & 0,63 \\
\hline $\mathrm{D}_{4}$ & 1 & 2 rasgo 2 & aff. Oreocereus spp. & 2 & o & 0,66 \\
\hline $\mathrm{D}_{4}$ & 1 & 2 rasgo 2 & Chenopodiaceae & 125 & 125 & 41,66 \\
\hline $\mathrm{D}_{4}$ & 2 & $1(\mathrm{NO})$ & aff. Oreocereus spp. & 1 & o & 0,39 \\
\hline $\mathrm{D}_{4}$ & 2 & $1(\mathrm{NO})$ & Chenopodiaceae & 7 & 7 & 2,74 \\
\hline $\mathrm{D}_{4}$ & 2 & 1 (E) & aff. Oreocereus spp. & 2 & 2 & 0,68 \\
\hline $\mathrm{D}_{4}$ & 2 & $1(\mathrm{E})$ & Chenopodiaceae & 4 & 4 & 1,37 \\
\hline $\mathrm{D}_{4}$ & 2 & $2(E)$ & aff. Oreocereus spp. & 4 & o & 1,21 \\
\hline $\mathrm{D}_{4}$ & 2 & $3(\mathrm{SO})$ & Chenopodiaceae & 1 & 1 & 0,5 \\
\hline $\mathrm{D}_{4}$ & 2 & 5 rasgo 9 & Chenopodiaceae & 1 & 1 & 0,35 \\
\hline
\end{tabular}

Tabla 5. Distribución y densidad de carporrestos en TAN-1, excluyendo Opuntia sp. Se destacan las máximas densidades de cada taxón en ambas unidades excavadas.

ambas unidades excavadas aunque de forma poco significativa en $\mathrm{C}_{4}$ (tres semillas). La principal concentración se encuentra en el rasgo 2 (41,66 sem/lt). Dentro de este conjunto se observaron tres semillas de mayor tamaño, esfericidad y pronunciamiento de la radícula (borde ecuatorial), determinadas como Chenopodium sp. (yuyo silvestre) (Tabla 5, Figura 8). Actualmente, las comunidades andinas del Norte Grande otorgan gran importancia a los diversos yuyos que crecen como malezas en las chacras. Los usos más recurrentes se vinculan con sus tallos y hojas tiernas, las cuales son utilizadas como alimento ya sea en ensaladas o caldos, y como forraje para los animales. Se reconoce también la importancia de sus hojas para preparar la llipta, pasta cenicienta usada para mascar hojas de coca. Antiguamente también se hacía harina de sus semillas para realizar "pagos" a los cerros, a los abuelos y a la Pachamama (Villagrán y Castro 2004).
Finalmente, del rasgo 4 de la unidad $\mathrm{C}_{4}$ se recuperó un conglomerado de material vegetal conformado por pajas, restos de bulbos y hojitas suculentas que hemos comparado con ejemplares actuales. Si bien la determinación efectiva de tallos (pajas) y hojas es conveniente realizarla a partir de análisis de cutícula, la identificación macroscópica, en este caso, ha sido efectiva por las particularidades propias de estos restos. Los primeros corresponden a paja blanca (Stipa sp. Familia Poaceae/ Graminae), cuyo crecimiento en ramilletes a partir de bulbos basales es un rasgo característico. Además, su textura suave la diferencia notablemente de la paja brava (Festuca sp.), que es la otra especie similar en el piso vegetacional precordillerano. Al mismo tiempo, el carácter suculento de las hojitas asociadas, nos llevó a compararlas con diferentes ejemplares de la familia Brassicaceae (o Cruciferae) aunque sin lograr hasta ahora una deter- 


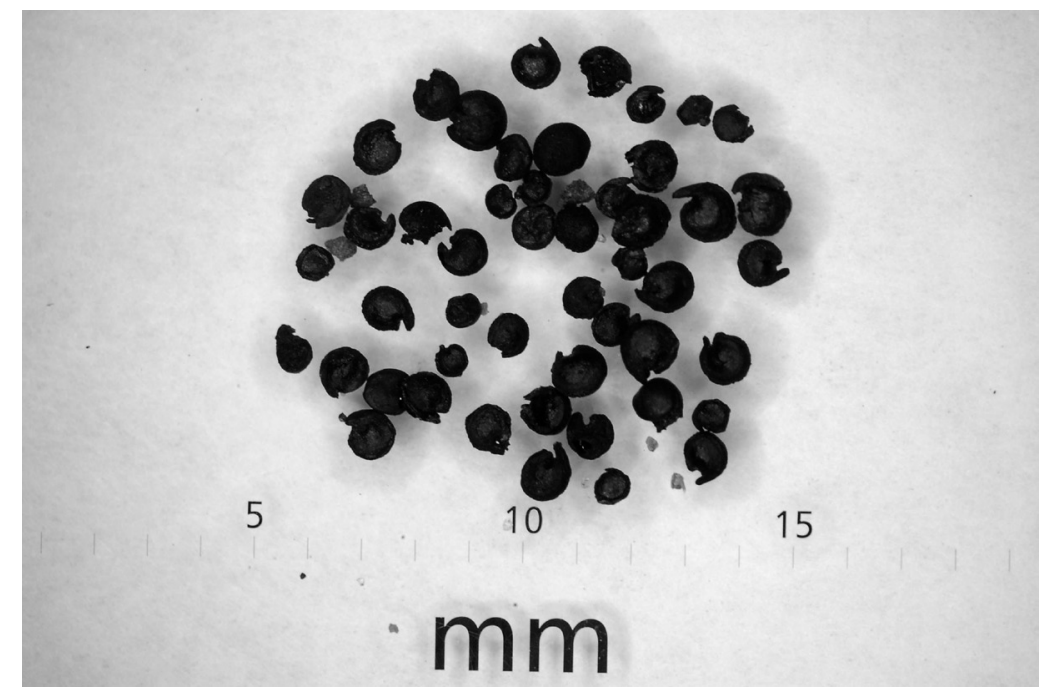

Figura 8. Semillas de yuyo silvestre (Chenopodium sp.), probablemente descartadas en la limpieza de sus tallos comestibles. TAN-1, unidad $\mathrm{C}_{2}$, nivel 1.

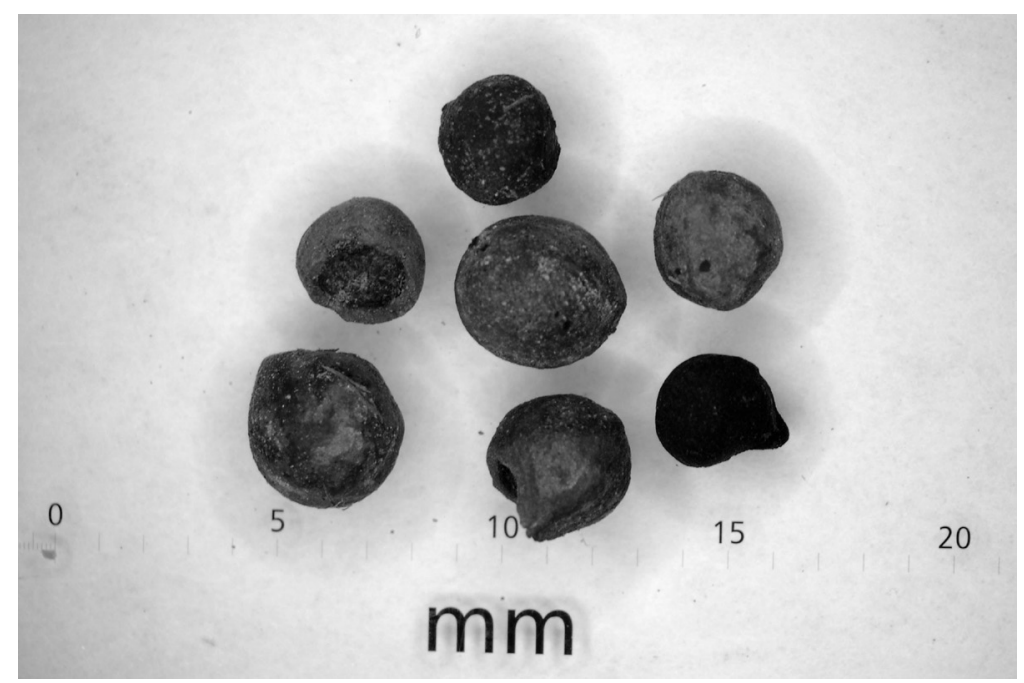

Figura 9. Conglomerado de pajas (Stipa sp.) y hojitas (Familia Brassicaceae). TAN-1, unidad C4, rasgo 4.

minación específica. El conglomerado registrado en el contexto arqueológico posee un tamaño aproximado de $50 \times 60 \mathrm{~cm}$ de diámetro y $15 \mathrm{~cm}$ de espesor, y en un primer momento creímos que se trataba de un nido de aves, lo cual fue posteriormente descartado debido a la ausencia de fecas. De esta manera, el conglomerado debió ser utilizado con alguna intención desconocida y que discutimos más adelante (Figura 9).

\section{* Discusión del análisis arqueobotánico}

Los contextos vegetales recuperados de los aleros Pampa del Muerto 3, Pampa del Muerto 8 y Tangani 1, dan cuenta, ante todo, de la importancia que tuvo la recolección de frutos de cactáceas. Específicamente, se ha reconocido la presencia de Opuntia sp. y otras semillas afines al género Oreocereus spp. que poseen frutos carnosos, de 
aspecto similar a la tuna, etnográficamente documentados como alimentos (Villagrán y Castro 2004; Pardo y Pizarro 2005; Novoa 2006). Durante las últimas décadas, y gracias a la aplicación de técnicas específicas, las semillas de cactáceas han sido halladas en otros contextos arqueológicos de la Puna, tanto en el Norte Grande de Chile como en Perú.

Por una parte, trabajos recientes en otros sitios arqueológicos de la precordillera de Arica han permitido hallar una semilla carbonizada de Opuntia sp. en el campamento Ipilla 2 y siete ejemplares de cactáceas afines a Oreocereus spp. en los aleros Cardones 1 y Cardones 2. Estos contextos presentan características similares a los aleros de Pampa del Muerto y Tangani, respecto de la cronología y discontinuidad de las ocupaciones, probablemente referidas a poblaciones que transitaban entre diferentes zonas ecológicas (García 2009 Ms).

La presencia de Opuntia sp. también ha sido documentada en la quebrada de Tulán, en los sitios Tu-52 y Tu54 correspondientes al Arcaico Tardío (fase Tulán) y al Formativo Temprano (fase Tilocalar), respectivamente. En estos sitios, la alta frecuencia de sus semillas -que constituye de igual modo el recurso vegetal más importante- se interpretaron como una intensificación de las actividades locales y expresión de una mayor permanencia, en relación con la movilidad propia que caracterizaría a los cazadores más tempranos (McRostie 2007). Específicamente, se menciona que "para el caso de Opuntia sp., la alta presencia y frecuencia de sus semillas en el Estadio Tilocalar, permite postular que sus frutos se estarían recolectando de una manera intensiva" (McRostie 2007: 37).

Paralelamente, en el alero Panaulauca (Perú Central), Pearsall (1988) analiza los macrorrestos vegetales de los estratos datados entre 3000 AC y 500-600 DC. Su análisis exploró la manera en que la abundancia de los restos era afectada por el origen y el contexto de depositación, proponiendo que el género Opuntia muestra pequeños cambios a través del tiempo, aunque manteniéndose siempre presente: "high presence and frecuency for Opuntia, by contrast, indicates a consistent use of cactus fruits as a casual food source" (Pearsall 1988: 109). Este proceso ocurre del mismo modo hasta la actualidad, pues los habitantes de la Puna consumen estos frutos de forma recurrente (Pearsall 1988: 104), al igual que en la Puna de Atacama.

Estos antecedentes son coherentes con el comportamiento de los restos estudiados, tanto en términos cronológicos como en la amplitud que caracteriza su distribución. Recapitulando, en PM-3 se registró un total de 105 semillas de Opuntia sp.; en PM-8, un total de 107 semillas pertenecientes al mismo género y dos identificadas como aff. Oreocereus spp. En TAN-1 contabilizamos 415 semillas de Opuntia sp. y 43 aff. Oreocereus spp. De acuerdo a ello, en TAN-1 se presenta la mayor concentración de ambos taxones, registrando 66\% de las semillas de Opuntia sp. y 96\% afines al género Oreocereus spp. (Tabla 6).

\begin{tabular}{|l|c|c|c|c|c|c|c|}
\cline { 2 - 8 } \multicolumn{1}{c|}{} & \multicolumn{2}{c|}{ PM-3 } & \multicolumn{2}{c|}{ PM-8 } & \multicolumn{2}{c|}{ TAN-1 } & Total \\
\cline { 2 - 8 } \multicolumn{1}{c|}{} & N & $\%$ & N & $\%$ & N & $\%$ & N \\
\hline Opuntia sp. & 105 & 16,75 & 107 & 17,07 & 415 & $\mathbf{6 6 , 1 9}$ & $\mathbf{6 2 7}$ \\
\hline aff. Oreocereus spp. & 0 & 0 & 2 & 4,44 & 43 & 95,56 & 45 \\
\hline
\end{tabular}

Tabla 6. Distribución absoluta y relativa de las semillas de cactáceas en los sitios estudiados.

Por otra parte, estratigráficamente se observa un comportamiento diferencial entre los distintos sitios que puede estar determinado por el carácter e intensidad de sus ocupaciones. No obstante, existe una gran coherencia en relación a su distribución entre las distintas unidades excavadas en un mismo sitio. De esta manera, en PM-3 la tendencia general de las semillas de Opuntia en las distintas unidades excavadas $\left(\mathrm{C}_{1}, \mathrm{C}_{5}\right.$ y $\left.\mathrm{D}_{2}\right)$ es de aumentar hacia los niveles intermedios (rasgos y niveles de la capa 2) donde se constata la mayor densidad (15,06 sem/lt). Desde ahí, la cantidad comienza a disminuir progresivamente hacia los niveles inferiores, llegando a la ocupación inicial (capa 4), con un índice de densidad nulo. En el caso de PM-8, la tendencia distribucional es diferente, ya que la mayor densidad de semillas de cactáceas, tanto Opuntia sp. como aquellas afines al género Oreocereus spp. se encuentran en los niveles superiores ( $55 \mathrm{sem} / \mathrm{lt}$ y $1,45 \mathrm{sem} / \mathrm{lt}$ ) de la única unidad excavada (B4) (Tabla 7). Por último, consideramos que en TAN-1 el comportamiento estratigráfico de estos restos es mucho más errático en ambas unidades 


\begin{tabular}{|l|c|c|c|c|c|c|}
\cline { 2 - 7 } \multicolumn{1}{c|}{} & \multicolumn{2}{c|}{ PM-3 } & \multicolumn{2}{c|}{ PM-8 } & \multicolumn{2}{c|}{ TAN-1 } \\
\cline { 2 - 7 } \multicolumn{1}{c|}{} & $\begin{array}{c}\text { Densidad } \\
\text { máx. }\end{array}$ & $\begin{array}{c}\text { Densidad } \\
\text { prom. }\end{array}$ & $\begin{array}{c}\text { Densidad } \\
\text { máx. }\end{array}$ & $\begin{array}{c}\text { Densidad } \\
\text { prom. }\end{array}$ & $\begin{array}{c}\text { Densidad } \\
\text { máx. }\end{array}$ & $\begin{array}{c}\text { Densidad } \\
\text { prom. }\end{array}$ \\
\hline Opuntia sp. & 15,06 & 2,8 & 55 & 11,81 & 37,69 & 8,25 \\
\hline aff. Oreocereus spp. & 0 & 0 & 1,45 & 0,22 & 8,46 & 0,85 \\
\hline
\end{tabular}

Tabla 7. Densidad de semillas de cactáceas en los sitios estudiados.

excavadas ( $\mathrm{C}_{4}$ y $\left.\mathrm{D}_{4}\right)$ ya que, si bien sigue una tendencia similar a PM-3 en cuanto la mayor densidad se presenta en los niveles intermedios (rasgos y niveles de la capa 2 con índices 37,69 sem/lt y $8,46 \mathrm{sem} / \mathrm{lt}$, respectivamente), disminuyendo en los superiores e iniciales, éstos se encuentran intercalados con niveles completamente estériles, señalando que, no todas las ocupaciones harían uso de estos frutos como alimentos, o bien, existía hiatos entre ellas (Tabla 7).

Por otra parte, entre las otras especies identificadas hemos señalado la presencia de maíz (Zea mays) en los niveles superiores de PM-3, el cual debido a su buen estado de preservación y posición estratigráfica, probablemente se asocia con una ocupación tardía del alero en momentos posteriores al período en que predomina el consumo de frutos de cactáceas. Asimismo, en PM-8 se registraron dos semillas de algarrobo (Prosopis sp.) asociadas a una mayor concentración de semillas de cactáceas (Opuntia sp.), dando cuenta que ambos tipos se consumieron sincrónicamente. A diferencia de las cactáceas representadas, el algarrobo no es una especie que actualmente se encuentre en el entorno de los aleros, no obstante, podría haber sido recolectado en quebradas cercanas más húmedas, como Saxamar y Belén. Como ya se ha mencionado, consideramos significativo el tipo de evidencia que representa tanto a las cactáceas como al algarrobo, ya que en ambos casos las semillas son desechos de consumo in situ, lo que implicaría el transporte de los frutos al interior de los aleros.

En TAN-1 las semillas de la familia Chenopodiaceae alcanzan una gran importancia con un total de 199 unidades cuantificadas, dentro de las cuales se distinguieron tres semillas de Chenopodium sp. (yuyo silvestre). Estas semillas (y la flor) debieron descartarse en el momento en que los tallos fueron limpiados para ser consumidos en estado fresco, siendo previamente recolectados en el entorno del alero (Villagrán y Castro 2004).

Por último, en relación al conglomerado de pajas (Stipa sp.) y hojitas (Familia Brassicaceae), no debemos descartar que corresponda a restos de una suerte de aislante, o a evidencia de preparación del piso del alero, considerando además que se trata de especies recurrentes en el ambiente y de fácil recolección y transporte. En el alero Quebrada Seca 3, en Antofagasta de la Sierra (Puna Meridional argentina), Rodríguez (1997-98) trabajó sobre el material vegetal proveniente del nivel vinculado al Arcaico Medio (ca. $7000 \mathrm{AP}$ ), pudiendo identificar camadas de paja, tanto de Deyeuxia eminens como Stipa sp., que formaban parte de la preparación de pisos ocupacionales y que por sus características otorgaban una superficie blanda apta para el descanso.

En síntesis, considerando la distribución actual de las especies, los restos vegetales asociados a los aleros estudiados corresponden en su mayoría a especies silvestres locales. De los ocho taxones identificados, por lo menos seis pueden recolectarse en el entorno más inmediato de los aleros (chenopodiáceas, cactáceas, brassicáceas y gramíneas), mientras que las otras dos (Prosopis sp. y Zea mays) provendrían de quebradas cercanas más húmedas y aptas para sustentar el crecimiento de especies arbóreas y agrícolas. Asimismo, se han documentado una diversidad de usos para muchas de las plantas identificadas (Tabla 8); no obstante, a juzgar por los tipos de evidencia a través de las cuales se encuentran representadas, y teniendo en cuenta el contexto arqueológico general, consideramos que éstas han sido requeridas en gran medida por su valor alimenticio. Esto permite sugerir que al interior de los aleros se consumieron frutos de cactáceas (Opuntia sp. y aff. Oreocereus spp.), vainas de algarrobo (Prosopis sp.), tallos de yuyo (Chenopodiaceae) y maíz 


\begin{tabular}{|l|c|c|c|}
\hline \multicolumn{1}{|c|}{ Nombre común } & Nombre científico & Evidencia & Usos etnográficos \\
\hline Yuyo & Chenopodium sp. Chenopodiaceae & Semilla & Alimentario, medicinal, forraje \\
\hline Jala jala, tuna, pega pega, kume, puskayo & Opuntia sp. Cactaceae & Semilla & Alimentario, medicinal, forraje, tintóreo \\
\hline Algarrobo, taracusa, yali & $\begin{array}{c}\text { Prosopis sp. } \\
\text { Fabaceae }\end{array}$ & Semilla & $\begin{array}{c}\text { Alimentario, forraje, leña, constructivo, } \\
\text { medicinal }\end{array}$ \\
\hline Sikuya, k'isi, paja blanca & $\begin{array}{c}\text { Stipa sp. } \\
\text { Poaceae/Graminae }\end{array}$ & Tallo y bulbo & Forraje, constructivo \\
\hline Maíz & $\begin{array}{c}\text { Zea mays } \\
\text { Poaceae }\end{array}$ & Mazorca & Alimentario, forraje, leña, medicinal \\
\hline Pichaja, tunilla, quisco, cardón blanco & Brassicaceae & Hoja & Alimentario \\
\hline & Crocereus spp. Cactaceae & Semilla & Alimentario, medicinal, forraje \\
\hline
\end{tabular}

Tabla 8. Restos vegetales encontrados en los aleros PM-3, PM-8 y TAN-1 y sus usos tradicionales documentados etnográficamente (Villagrán y Castro 2004; Pardo y Pizarro 2005; Novoa 2006).

(Zea mays). En este sentido, las únicas plantas diferentes serían las pajas y hojitas, las cuales, en TAN-1, podrían asociarse a actividades de descanso.

\section{* Nuevas interpretaciones para los aleros CON PINTURAS DE LA PRECORDILlERA DE ARICA}

Los aleros de Pampa del Muerto fueron inicialmente interpretados en relación a ocupaciones de poca o corta actividad, asociados a momentos incaicos, como espacios de caza para pobladores provenientes de aldeas vecinas de las localidades de Belén y Saxamar (Santoro y Dauelsberg 1985). En este contexto, las pinturas testimoniarían prácticas ceremoniales vinculadas con la caza, dado que la topografía del lugar y la presencia de profundas y estrechas quebradas habrían conformado espacios aptos para acorralar a los camélidos salvajes. Sin embargo, pese a las evidencias excavadas, Santoro y Dauelsberg (1985) reconocen varios indicios que permiten suponer una mayor antigüedad para las pinturas, en relación con las ocupaciones de cazadores recolectores del período Arcaico.

Posteriormente, y profundizando en esta última interpretación, Muñoz y Briones (1996) proponen la ocupación del sector por parte de grupos cazadores especializados y relacionados con las pinturas de escenas de cacería en un estilo que ellos definen como "depurado". Complementariamente, plantean un segundo momento de ocupa- ción de los aleros durante el período Intermedio Tardío o Desarrollos Regionales, vinculado a grupos caravaneros que transitarían por estos espacios e interactuarían con grupos ganaderos locales.

A diferencia de Pampa El Muerto, los primeros registros de Tangani los obtuvo Niemeyer (1972), que resume su investigación desarrollada a fines de la década del 60 . En ese entonces, excava y describe 18 sitios en la precordillera, obteniendo instrumentos líticos, restos óseos y cerámica, lo que lo llevan a atribuir la ocupación de los aleros a grupos agroalfareros tardíos de la Cultura Arica (1000-1400 DC). Sin embargo, Niemeyer reconoce que las manifestaciones rupestres de la precordillera de Arica se inscriben dentro de una larga tradición, sugiriendo una mayor antigüedad en relación a la expresada por los materiales rescatados (Niemeyer 1972).

Posteriormente, reformularía esta postura a raíz de los trabajos efectuados en los aleros Itiza y Mullipungo, en el sector alto de la cuenca de Camarones, planteando que el estilo de las representaciones rupestres podría insertarse en una tradición agropastoril cuya función se vincularía a ceremonias ligadas a la caza (Schiappacasse y Niemeyer 1996):

"[...] al igual que en Piñuta [Santoro y Dauelsberg (1985)], el alero de Itiza debe entenderse como formando parte de un sistema de asentamiento de comunidades aldeanas agropasto- 
riles y que complementan sus recursos con actividades de caza" (Schiappacasse y Niemeyer 1996: 274).

Las nuevas excavaciones realizadas, junto a las evidencias contextuales obtenidas y el estudio de los restos vegetales y líticos, permiten precisar para el Arcaico Tardío ocupaciones discretas e intermitentes que arrojaron materiales diversos, aunque en la mayoría de los casos, en muy bajas proporciones: pequeños fogones, alimentos recolectados del entorno y otros transportados (conchas del Pacífico), desechos de talla lítica bifacial e instrumentos expeditivos de usos cortantes (Carrasco 2009 Ms). Su evaluación sistemática esclarece las formas de ocupación de estos sitios a los que se accedió por tiempos muy acotados con el fin de realizar actividades específicas vinculadas fundamentalmente con la caza de camélidos salvajes y, posiblemente tarucas, animales que se observan en los paneles pintados. Lo anterior también está avalado por una cornamenta de taruca usada como percutor blando para la talla lítica en PM-8 (Sepúlveda et al. 2010 Ms). Una vez concluidas sus actividades, los grupos humanos abandonaron los aleros para regresar a sus lugares de origen ( $\mathrm{u}$ otros), para posteriormente volver a reocuparlos de manera ocasional. La ausencia de cantidades considerables de restos óseos y la escasez de instrumentos formatizados llevan a pensar que tanto los animales cazados como las herramientas bifaciales se iban junto con los ocupantes del alero. Nuestros resultados no niegan la posibilidad de que los aleros hayan sido ocupados en etapas ulteriores, relacionadas con actividades de caravaneo o pastoreo e incorporándose a un patrón de asentamiento tardío donde los pucara y las grandes aldeas se transforman en centros gravitantes (Muñoz y Chacama 2006). Sin embargo, las evidencias apuntan a una mayor ocupación en épocas tempranas, ya que los materiales tardíos se encuentran en superficie y son bastante escasas.

Para el Formativo Temprano, otros vestigios materiales asociados a los aleros estudiados, como plumas de colores y pequeños restos de minerales de cobre, demuestran que posiblemente éstos fueron ocupados por individuos que transitan entre diferentes zonas y pisos ecológicos. Asimismo, el hallazgo de una tortera de cerámica en PM-3 indica que ocupaciones datadas en el Formativo Temprano podrían dar cuenta de la presencia de animales domésticos y, en este sentido, los ocupantes no necesariamente serían sólo cazadores, sino también pastores.
De esta manera, hasta ahora es posible vincular las escenas pintadas de los aleros con el uso doméstico de estos espacios, y acotado temporalmente en relación con actividades de alimentación y descanso. Sobre la primera actividad, debieron ser importantes los alimentos recolectados en el entorno, principalmente los frutos de cactáceas (Opuntia sp. y aff. Oreocereus spp.) y tallos de yuyo (Chenopodiaceae), los cuales se consumieron alrededor de pequeños fogones donde se descartaron estas semillas, explicando de este modo su carbonización. La actividad de descanso, sugerida por el conglomerado de pajas (Stipa sp.) y hojitas suculentas (Brassicaceae), permite a su vez, identificar procesos de preparación del piso con el fin de obtener una superficie más blanda para descansar. En este sentido, los restos vegetales han permitido analizar más finamente la intensidad de las distintas ocupaciones que se suceden en el tiempo al interior de cada alero. TAN-1 es el más elocuente de ellos al presentar cambios notorios en la densidad de los restos entre una ocupación y otra. Estas diferencias podrían señalar su utilización en distintas estaciones del año, probablemente durante el invierno y la primavera cuando no hay frutos de cactáceas, o bien, mostrar diferentes tendencias de ocupar un mismo espacio.

Los resultados obtenidos constituyen un fragmento de una investigación mayor; sin embargo, nos recuerdan la importancia de rescatar los contextos vegetales en zonas donde este tipo de estudio ha sido escasamente abordado, destacando la utilidad de estos análisis en sitios con poca densidad depositacional en estratigrafía. La gran cantidad de pinturas rupestres con superposiciones de imágenes demuestran el uso reiterado de estos aleros precordilleranos. Estos análisis permiten precisar el tipo de actividades desarrolladas en ellos así como aproximarnos a sus autores, especificando los contextos de uso (sensu Aschero 2006) relacionados con las pinturas rupestres de la precordillera de Arica, aspecto todavía poco abordado en esta región donde abundan estos tipos de registros.

Agradecimientos Este trabajo ha sido realizado en el marco del Proyecto FONDECYT 11060144. Agradecemos a Calogero Santoro por facilitarnos el laboratorio Lluta (Museo Universidad de Tarapacá, San Miguel de Azapa) para el análisis de los restos vegetales, y a Claudio Latorre por compartir su herbario con nosotros y contribuir con bibliografía específica para la determinación de los restos. 


\section{* Referencias citadas}

ASCHERO, C., 2006. De cazadores y pastores. El arte rupestre de la modalidad río Punilla en Antofagasta de la Sierra (Puna Meridional argentina). En Tramas en La Piedra, D. Fiore y M. M. Podestá (Eds.), pp. 103-140. Sociedad Argentina de Antropología y Asociación Amigos del Instituto Nacional de Antropología, Buenos Aires.

AYALA, P., 2001. Las sociedades del Altiplano Circumtiticaca y Meridional y su relación con el Norte Grande de Chile. Estudios Atacameños 21: 7-39.

BELMONTE, E., I. MUÑOZ e Y. MOLINA, 1995. Contenido orgánico de un yacimiento habitacional de cazadores recolectores en la desembocadura del río Camarones: El caso de Camarones 8. Actas del XIII Congreso Nacional de Arqueología Chilena, vol. 1, pp. 35-44. Universidad de Antofagasta, Antofagasta.

BELMONTE, E., E. BASTÍAS, M. GÓMEZ, A. MUJICA y G. MONTENEGRO, 2001. Determinación taxonómica de fragmentos de madera de contexto funerario de la cultura Chinchorro. Chungara 33: 145-154.

CARRASCO, C., 2009 Ms. Informe de análisis de material lítico de aleros rocosos de la precordillera de Arica. Informe Proyecto FONDECYT 11060144, Santiago.

CHACAMA, J., 2004. El Horizonte Medio en los Valles Occidentales del norte de Chile (ca. 500-1200 DC). Chungara 36 vol. especial (1): 227-233.

DAUELSBERG, P., 1974. Excavaciones arqueológicas en Quiani. Chungara 4: 7-38.

1985. Faldas del Morro. Fase agroalfarera temprana. Chungara 14: 7-44.

ERICES, S., 1975. Evidencias vegetales de tres cementerios prehispánicos (Arica, Chile). Chungara 5: 65-71.

FOCACCI, G., 1974. Excavaciones en el cementerio de playa Miller. Chungara 3: 23-74.

1980. Síntesis de la arqueología del extremo norte de Chile. Chungara 6:3-23.

GARCÍA, M., M. GARDEWEG, J. CLAVERO y G. HÉRAIL, 2004. Carta geológica de Chile. Serie Geología Básica 84. Hoja AricaRegión de Tarapacá. Escala 1:250.000. Subdirección Nacional de Geología, Servicio Nacional de Geología y Minería, Santiago.

GARCÍA, M., 2007. Plantas y arqueología del Complejo PicaTarapacá (ca. 1250-1450 DC). Espacio doméstico, contexto de uso y asociaciones materiales. Memoria de título en Arqueología, Facultad de Ciencias Sociales, Universidad de Chile, Santiago.

2009 Ms. El material vegetal de los sitios Ipilla 2 y Cardones 1 y 2, precordillera de Arica. Informe Proyecto FONDECYT 7070320, Santiago.

HASTORF, C. y V. POPPER, 1988. Current paleoethnobotany. Analytical methods and cultural interpretations of archaeological plant remains. The University of Chicago Press, Chicago.

HOFFMANN, A., 1989. Cactáceas en la flora silvestre de Chile. Ediciones Fundación Claudio Gay, Santiago.

McROSTIE, V., 2007. La transición Arcaico-Formativo en la quebrada de Tulan, sur del Salar de Atacama, Chile. Evidencias arqueobotánicas. Memoria de Título en Arqueología, Facultad de Ciencias Sociales, Universidad de Chile, Santiago.

MUÑOZ, I., 1982. Las sociedades costeras en el litoral de Arica y sus vinculaciones con la costa sur peruana. Chungara 9: 124151.

1989. El período Formativo en el Norte Grande (1000 AC500 DC). En Culturas de Chile. Prehistoria. Desde sus Orígenes a los albores de la Conquista, J. Hidalgo, V. Schiappacasse, H. Niemeyer, C. Aldunate e I. Solimano (Eds.), pp. 107-128. Editorial Andrés Bello, Santiago.

2001. Uso de plantas en rituales funerarios del período Formativo en Arica. Chungara 33 (1): 155-160.

2004. El período Formativo en los valles del norte de Chile y sur de Perú: Nuevas evidencias y comentarios. Chungara vol. especial (1): 213-225.

MUÑOZ, I. y L. BRIONES, 1996. Poblados, rutas y arte rupestre precolombinos de Arica: Descripción y análisis del sistema de organización. Chungara 28 (1-2): 47-84.

MUÑOZ, I. y J. CHACAMA, 2006. Complejidad social en las alturas de Arica: Territorio, etnicidad y vinculación con el Estado inca. Ediciones Universidad de Tarapacá, Arica.

NIEMEYER, H., 1972. Las pinturas de la Sierra de Arica. Editorial Gerónimo de Bibar y Editorial Universitaria, Santiago.

NOVOA, S., 2006. Sobre el origen de la tuna en el Perú. Algunos alcances. Zonas Áridas 10: 174-181. 
NÚÑEZ, L. 1969. Sobre los complejos culturales Chinchorro y Faldas del Morro del norte de Chile. Rehue 2: 111-142.

1989. Hacia la producción de alimentos y la vida sedentaria (5000 AC-900 DC). En Culturas de Chile. Prehistoria. Desde sus orígenes a los albores de la Conquista, J. Hidalgo, V. Schiappacasse, H. Niemeyer, C. Aldunate e I. Solimano (Eds.), pp. 81-106. Editorial Andrés Bello, Santiago.

NÚÑEZ, L. y T. DILLEHAY, 1995 [1978]. Movilidad giratoria, armonía social y desarrollo en los Andes Meridionales: Patrones de tráfico e interacción económica. Universidad Católica del Norte, Antofagasta.

NÚÑEZ, L. y V. STANDEN, 1984. Indicadores antropológico-físicos y culturales del cementerio precerámico Tiliviche 2 (norte de Chile). Chungara 12:135-153.

OGALDE, J. P. y M. SEPÚLVEDA, 2009 Ms. Análisis químicos en terreno y procesos de formación de sitio. Un caso de estudio en el extremo norte de Chile. Manuscrito en poder de los autores.

PARDO, O. y J. L. PIZARRO, 2005. Especies botánicas consumidas por los chilenos prehispánicos. Colección Chile Precolombino, Editorial Mare Nostrum, Santiago.

PEARSALL, D., 1988. Interpreting the meaning of macroremain abundance: The impact of source and context. En Current paleoethnobotany. Analytical methods and cultural interpretations of archaeological plant remains, C. Hastorf y V. Popper (Eds.), pp. 97118. The University of Chicago Press, Chicago.

1989. Paleoethnobotany. A handbook of procedures. Academic Press, Inc. University of Missouri, Missouri.

RIVERA, M., 1975. Una hipótesis sobre movimientos poblacionales altiplánicos y trans-altiplánicos a la costa del norte de Chile. Chungara 5: 7-31.

1994. Hacia la complejidad social y política: El desarrollo Alto Ramírez del norte de Chile. Diálogo Andino 13: 11-25.

RIVERA, M., P. SOTO, L. ULLOA y D. KUSHNER, 1974. Aspectos sobre el desarrollo tecnológico en el proceso de agriculturización en el norte prehispánico, especialmente en Arica, Chile) Chungara 3: 79-107.

RODRÍGUEZ, M. F., 1996-98. Propuesta metodológica para el análisis de macrovestigios vegetales. Presentación de un caso: Quebrada Seca 3, nivel 2B (12). Palimpsesto 5: 238-248.

SÁNCHEZ, H. y A. MELGAREJO, 2009. Estudio químico preliminar y comparativo entre un suelo de alero arqueológico y un suelo natural circundante. Memoria para optar al título de Quí- mico Laboratorista, Departamento de Química, Universidad de Tarapacá, Arica.

SANTORO, C., 1981 Estratigrafía y secuencia cultural funeraria. Fases Azapa, Alto Ramírez y Tiwanaku (Arica, Chile). Chungara 6: $24-45$.

1982. Formativo Temprano en el extremo norte de Chile. Chungara 8: 33-62.

1989. Antiguos cazadores de la Puna (9000 a 6.000 AC). En Culturas de Chile. Prehistoria. Desde sus orígenes hasta los albores de la Conquista, J. Hidalgo, V. Schiappacasse, H. Niemeyer, C. Aldunate e I. Solimano (Eds.), pp. 33-56. Editorial Andrés Bello, Santiago.

2000. Formativo en la región de Valles Occidentales del área Centro Sur Andina (sur de Perú-norte de Chile). En Formativo Sudamericano, una reevaluación, P. Ledergerber (Ed.), pp. 243-254. Ediciones Abya-Yala, Quito.

SANTORO, C. yJ. CHACAMA, 1982. Secuencia cultural de las tierras altas del área Centro Sur Andina. Chungara 9: 22-45.

SANTORO, C. y P. DAUELSBERG, 1985. Identificación de indicadores tempo-culturales en el arte rupestre del extremo norte de Chile. En Estudios en Arte Rupestre. Primeras Jornadas de Arte y Arqueología, C. Aldunate, J. Berenguer y V. Castro (Eds.), pp. 6986. Museo Chileno de Arte Precolombino, Santiago.

SANTORO, C., V. STANDEN, J. HIDALGO y J. CHACAMA, 2003. Historia de los pueblos prehispánicos que habitaron la región de Tarapacá. En Conozcamos juntos la historia y cultura de nuestra región, A. M. Carrasco y B. Cofré (Eds.), pp. 15-38. EXPLORA, Gore de Tarapacá, Centro de Investigaciones del Hombre en el Desierto (CIHDE) y Taller de Estudios Andinos (TEA), Arica.

SCHIAPPACASSE, V. y H. NIEMEYER, 1984. Arcaico Temprano en la quebrada de Camarones. Publicación Ocasional del Museo Nacional de Historia Natural 41.

1996. Las pictografías de los aleros de Itiza y de Mullipungo de la Sierra de Arica. Chungara 28 (1-2): 253-276.

SEPÚLVEDA, M., 2008. Pinturas rupestres de la precordillera de Arica (norte de Chile). Re-evaluación a 40 años de la obra pionera de Hans Niemeyer. Boletín SIARB 22: 68-79.

SEPÚlVEDA, M., M. GARCÍA y C. CARRASCO, 2009 Ms. Contextos arqueológicos y pinturas rupestres de la precordillera de Arica (extremo norte de Chile). Manuscrito en poder de los autores. 
SEPÚLVEDA, M., W, FAÚNDEZ y T. SAINTENOY, 2010 Ms. Pinturas rupestres de la precordillera de Arica, extremo norte de Chile. Propuesta estilística, cronología relativa y posibles interpretaciones. Manuscrito en poder de los autores.

STANDEN, V., 1991. El cementerio Morro 1: Nuevas evidencias de la tradición funeraria Chinchorro (Período Arcaico, norte de Chile). Tesis para optar al grado de magíster en Arqueología, Pontificia Universidad Católica del Perú, Lima.

VIDAL, A., 2010. Evaluación de la evidencia arqueobotánica durante el Período Formativo en el Norte Grande de Chile. Werkén 12 : 61-76.
VILLAGRÁN, C. y V. CASTRO, 2004. Ciencia indígena de los Andes del norte de Chile. Editorial Universitaria, Santiago.

VILlAGRÁN, C., V. CASTRO, G. SÁNCHEZ, M. ROMO, C. LATORRE y L. F. HINOJOSA, 1998. La tradición surandina del desierto: Etnobotánica del área del Salar de Atacama (provincia de El Loa, región de Antofagasta). Estudios Atacameños 16: 7-106.

VILLAGRÁN, C., V. CASTRO, G. SÁNCHEZ, F. HINOJOSA y C. LATORRE, 1999. La Tradición Altiplánica: Estudio etnobotánico en los Andes de Iquique, I región, Chile. Chungara 31 (1): 81-186. 